TI 2011-152/4

Tinbergen Institute Discussion Paper

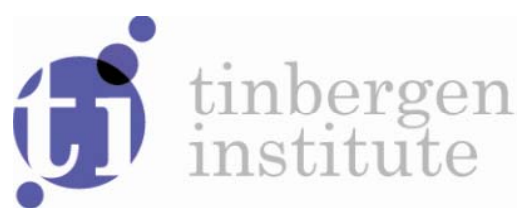

\title{
The Impact of Mobile Telephone Use on Economic Development of Households in Uganda
}

Sanne Lise Blauw

Philip Hans Franses 
Tinbergen Institute is the graduate school and research institute in economics of Erasmus University Rotterdam, the University of Amsterdam and VU University Amsterdam.

More TI discussion papers can be downloaded at http://www.tinbergen.nl

Tinbergen Institute has two locations:

Tinbergen Institute Amsterdam

Gustav Mahlerplein 117

1082 MS Amsterdam

The Netherlands

Tel.: +31(0)205251600

Tinbergen Institute Rotterdam

Burg. Oudlaan 50

3062 PA Rotterdam

The Netherlands

Tel.: +31(0)10 4088900

Fax: $+31(0) 104089031$

Duisenberg school of finance is a collaboration of the Dutch financial sector and universities, with the ambition to support innovative research and offer top quality academic education in core areas of finance.

DSF research papers can be downloaded at: http://www.dsf.nl/

Duisenberg school of finance

Gustav Mahlerplein 117

1082 MS Amsterdam

The Netherlands

Tel.: +31(0)20 5258579 


\title{
The impact of mobile telephone use on economic development of households in Uganda*
}

\author{
Sanne Lise Blauw ${ }^{\dagger}$ \\ Philip Hans Franses
}

October 28, 2011

\begin{abstract}
We examine the impact of mobile telephone use on economic development of individual households. Unique cross-sectional data were collected in personal interviews with heads of households ( $\mathrm{N}=196)$ in Uganda. Economic development is measured at the household level by the Progress out of Poverty Index ${ }^{\mathrm{TM}}$. We find strong support that mobile phone use positively impacts economic development.
\end{abstract}

Keywords: Economic development; Progress out of Poverty Index ${ }^{\mathrm{TM}}$; mobile telephone; mobile banking; mobile search.

JEL code: $\mathrm{I} 3$

\footnotetext{
${ }^{*}$ We are grateful to Oikocredit the Netherlands and the Erasmus Trust Fund for financial support. At a personal level we are thankful to Tolophisa, Moses and Jackson, who introduced the first author to the interviewees and interpreted where necessary. Further mention should go to SYPO, where Emma helped to organize the data collection and Christine contributed much by helping to translate the questionnaire to Luganda. We further thank Dick van Dijk for his helpful suggestions.

${ }^{\dagger}$ Econometric Institute, Erasmus School of Economics, PO Box 1738, NL-3000 DR Rotterdam, The Netherlands, email: blauw@ese.eur.nl (corresponding author)
} 
Tinbergen Institute is the graduate school and research institute in economics of Erasmus University Rotterdam, the University of Amsterdam and VU University Amsterdam.

More TI discussion papers can be downloaded at http://www.tinbergen.nl

Tinbergen Institute has two locations:

Tinbergen Institute Amsterdam

Gustav Mahlerplein 117

1082 MS Amsterdam

The Netherlands

Tel.: +31(0)205251600

Tinbergen Institute Rotterdam

Burg. Oudlaan 50

3062 PA Rotterdam

The Netherlands

Tel.: +31(0)10 4088900

Fax: $+31(0) 104089031$

Duisenberg school of finance is a collaboration of the Dutch financial sector and universities, with the ambition to support innovative research and offer top quality academic education in core areas of finance.

DSF research papers can be downloaded at: http://www.dsf.nl/

Duisenberg school of finance

Gustav Mahlerplein 117

1082 MS Amsterdam

The Netherlands

Tel.: +31(0)20 5258579 


\section{Introduction}

It is now widely understood that mobile phone use has beneficial effects on economic development in developing countries. Usually, such development is measured by market participation by farmers or by aggregate indicators of economic prosperity. In this paper we aim to add to the knowledge base by studying the impact of mobile phone use on household-specific economic development. For that purpose we conducted personalized interviews in Uganda, which amounted to data on about 200 households. A second novelty of our study is that we use the Progress out of Poverty Index ${ }^{\mathrm{TM}}$, which we here use as a variable to be explained. After applying the proper econometric estimation techniques, we document that mobile phone use indeed has beneficial effects at household-specific development.

\section{Background}

Mobile phone user rates have increased rapidly in developing countries. Africa, for example, had a density of $40 \%$ at the end of 2008 (The Economist, 2009a), with a 59.7\% annual growth rate of mobile phones per 100 habitants between 1999 and 2004 (Telecommunications Union, 2007). This increase in mobile telephone activity is often cited as one of the fundamental causes of recent boosts to development in the developing world. An important explanation for the positive and sizable impact of the mobile phone is its power to enhance market efficiency. Buyers and sellers in developing countries often lack the means to evaluate prices, and this could cause that markets become inefficient (Eggleston et al., 2002) which would be noticeable from price dispersion (Stigler, 1961). Telephones enable market agents to collect information for their buying or selling decisions, and this makes markets more efficient. Jensen (2007), for example, presents empirical evidence that a "near-perfect adherence to the Law of One Price" in the South Indian fisheries sector is due to mobile phone use. Additionally, mobile phones can induce time savings and reduced travelling costs (Mittal et al., 2009). The public phone, used as a substitute or a complement to the mobile phone, has also been found to have positive effects on economic development (Bayes et al., 1999).

The economic impact of mobile phones in the developing world is twice as large as in 
developed countries (Waverman et al., 2005). Interestingly, unlike their developed counterparts, developing countries have leapfrogged fixed telephone lines and moved straight to using mobile phones. Indeed, both mobile and public phones seem to close the digital divide between the developed and developing world, in fact facilitating a "Digital Provide", which ultimately leads to economic growth (Eggleston et al., 2002).

The expanding trend in mobile phone users is mirrored by the rapidly increasing number of mobile applications. A significant recent application is mobile banking (m-banking), which allows customers to store, to transfer and to withdraw money using their mobile phones. Undoubtedly, M-PESA in Kenya is the most successful example of m-banking in the developing world (The Economist, 2009b). Since M-PESA's launch in 2007, its customer base has grown to $23 \%$ of the Kenyan population and the transactions amount to $11 \%$ of Kenya's GDP (The Economist, 2010). M-banking is expected to have a positive effect on economic development, for reasons of financial security, informal sector reduction and entrepreneurship (Coyle, 2007).

Another recent trend in mobile phone applications is "mobile search", encompassing a range of Short Message Service (SMS) services that inform users on request of weather conditions, sports, news, agriculture, health and so on. Mobile search allows efficient gathering of information, and it helps individuals to take more informed decisions. An example of such a service is Google SMS in Uganda, which enables users to ask for specific health information (like family planning) or agricultural information (like tick control on livestock).

All these recent applications hinge upon the availability and use of mobile phones, and therefore we address the latter as the key focus of our paper. We decided to collect data at the household level, as, to the best of our knowledge, no such detailed data are available. More precise, we collected survey data for 196 households in Uganda. ${ }^{1}$ Using these detailed data, our study investigates the impact on economic development of mobile phone use. We use the Progress out of Poverty Index ${ }^{\mathrm{TM}}$ - developed by the Grameen Foundation - to measure economic

\footnotetext{
${ }^{1}$ Uganda is an interesting country for its pioneering role in telephones. It was the first to replicate the Village Phone program outside of Bangladesh, where it was initiated by the Grameen Foundation, and recently Uganda launched the Google SMS application. MTN villagePhone in Uganda is initiated by the telephone provider MTN Uganda and the Grameen Foundation. The program establishes so-called village phone operators (VPOs) in villages which lack electricity and provides them with a cell phone, which villagers can use for a small charge.
} 
development at the household level, which is the first time that this variable is used as a variable to be explained.

The remainder of this paper is as follows. Section 2 provides an overview of the literature on impact studies of basic and advanced telephone use. Section 3 discusses the data collection. Section 4 describes the econometric methodology and it presents the empirical results. Finally, Section 5 provides conclusions, a discussion, and suggestions for future research.

\section{Literature}

Donner (2008) provides the most comprehensive review of mobile phone studies in the developing world, surveying about 200 articles and allocating them to various categories. Our study can be associated with Donner's "mobile impact" category, which focuses on developmental effects of mobile phones. Note that all studies in this category are reported to conclude that mobile phone use has a significant positive impact on economic development.

Mobile phone impact studies view economic development from either a macro-economic or a micro-economic standpoint. A precursor to the macro-economic studies is Hardy (1980), who found a positive impact of fixed line telephones on economic growth. Waverman et al. (2005) also find a positive significant effect of mobile telecommunications on economic growth and emphasize that this impact "may be twice as large in developing countries compared to developed countries." In addition, Waverman et al. (2005) report absolute price and income elasticities of mobile phone demand larger than 1. Likewise, Kathuria et al. (2009) show that Indian states with higher mobile phone penetration have a higher economic growth.

There are various studies that report on the micro-economic impact of mobile phones. These studies tend to focus on the market effects of mobile phone use. Abraham (2007), for example, shows that the use of mobile phones has a positive impact on economic development in the fishing industry in India, which is established through increased market integration, gains in productivity and reduction of price dispersion and price fluctuations. Similarly, Aker (2008) finds that the grain prices across Nigerian markets have been reduced by $20 \%$ as a result of mobile phone use. Aker (2008) utilizes the "quasi-experimental nature of cell-phone rollout" 
and examines changing market power. Jensen (2007) demonstrates a "near-perfect adherence to the Law of One Price" in the South-Indian fisheries sector. Muto and Yamano (2009) find that mobile phone coverage expansion increases market participation in Uganda for farmers growing perishable crops in remote areas.

In contrast to the available micro-economic studies, our present study focuses on the impact on individual households rather than on markets. It is yet unclear whether or not individuals can directly influence their household's development by using a mobile phone. Any evidence of such an impact at the household level could catalyze further investments in pro-poor telecommunications.

It is difficult to measure economic development at the household level in developing countries, simply because clear income documentation is usually not available. We therefore choose to use the Progress out of Poverty Index ${ }^{\mathrm{TM}}\left(\mathrm{PPI}^{\mathrm{TM}}\right)$ from Chen et al. (2008) as a convenient measure. The index, developed by the Grameen Foundation, has so far only been used by microfinance institutions to track their borrower's development. Our study is the first to attempt to explain $\mathrm{PPI}^{\mathrm{TM}}$ in a statistical model, linking $\mathrm{PPI}^{\mathrm{TM}}$ with mobile phone use and other variables.

As Donner (2008) proposes, future research should "disaggregate the artifact" of the mobile phone, meaning that researchers should analyze different features of mobile phone use. The mobile phone went through a rapid expansion of its possibilities, complementing phone calls and SMS. Our study uses unique data to evaluate the impact of two recent developments in mobile telephony, that is, m-banking and mobile search. As both applications have been introduced in the developing world only recently, impact studies are rare. We shall use descriptive statistical tools to examine whether these new possibilities can be associated with higher economic development at the household level.

M-banking enables individuals to use their mobile phone as a portable bank account for the purpose of storing, transferring and withdrawing money. In developing countries the service is most often performed via SMS. Most m-banking research is restricted to studying adoption (Laforet and Li, 2005) or use (Porteous, 2007; Ivatury and Pickens, 2002). Porteous (2007) and Ivatury and Pickens (2002) make the case that m-banking users in South Africa are more 
educated and richer than South Africans with a regular bank account. Ivatury and Mas (2008) address the "early adopter" characteristics of users and predict that in the future m-banking will be used more by poor than by rich individuals. One of the rare quantitative impact studies is cited by The Economist (2009b) stating that "incomes of Kenyan households using M-PESA ${ }^{2}$ have increased by 5-30\% since they started mobile banking." Duncombe and Boateng (2009) state that "academic research . . . is lagging behind the rapid change on the ground." Duncombe and Boateng (2009) emphasize the need for impact evaluation at a micro level using primary data, and this is what we will do in our present study.

Mobile search services send information on a wide range of topics in the form of text messages. The important difference from other SMS information services is that mobile search services send information on request of the user. At the more general level of SMS services, there is a "growing body of evidence" that "pro-poor services" using SMS have a positive impact (Scott et al., 2004). Literature on mobile search is mainly of a technological nature, such as Jones et al. (2007), and/or focused on developed countries, like Kamvar and Baluja (2006). Our study is the first mobile search impact study in the developing world.

In addition to mobile phones, our study also includes public phone use. Bayes et al. (1999), which is one of the rare public phone impact studies, claim that Grameen Telecom's village phone program, which provides public phones to rural areas, has proven to reduce poverty of its users in Bangladesh.

To summarize, we study the micro-economic impact of mobile phones by using the PPI ${ }^{\mathrm{TM}}$ to measure development at the household level. Additionally, we investigate the impact of mbanking and mobile search in a developing country.

\section{Data collection}

Our cross-sectional data set contains variables concerning economic development at the household level, telephone use and household characteristics. Unique data were collected by the first

\footnotetext{
${ }^{2}$ The 'M' in M-PESA refers to 'mobile' and pesa means 'money' in Swahili.
} 
author in interviews with heads of households $(\mathrm{N}=196)$ on location in Uganda in March $2010 .^{3}$

To account for the geographic diversity of Uganda, we selected three different areas as interview locations. Area 1 is located in the Central region of Uganda, in the Buikwe county in the Mukono district. Area 2 is in Eastern Uganda, in the Tingey county in the Kapchorwa district, Area 3 is in Western Uganda, in the Busongora county in the Kasese district. The map in Figure 1 indicates the locations of these areas. Interpreters assisted us in conducting the interviews in each of the three areas, translating to/from the languages of Luganda, Kuksabiny, and Logongo/Lutoro respectively. The remainder of this section describes the economic development, telephone use and household characteristics. Table 7 in Appendix A provides an overview and description of all variables discussed in our study.

\section{Economic Development}

We measure the economic development of a household by the Progress out of Poverty Index ${ }^{\mathrm{TM}}$ $\left(\mathrm{PPI}{ }^{\mathrm{TM}}\right)$. This index, which has been developed by the Grameen Foundation, is gaining popularity in microfinance as it provides a rough-and-ready measurement of development. The index is calculated using a scorecard containing a few simple questions, which allows for quick answering. Each item is associated with points, and the sum of the points for all questions is equal to the PPI ${ }^{\mathrm{TM}}$ for the household of the interviewee. As a formal scorecard is not yet available for Uganda, we use the PPI ${ }^{\mathrm{TM}}$ for the neighboring country Kenya, as outlined in Chen et al. (2008). Table 1 displays this scorecard. In Appendix D, Table 8 shows a statistical summary of our data. The index ranges from 0 to 100, and a high (low) score indicates a low (high) probability that a household is below the poverty line. We interpret the PPI ${ }^{\mathrm{TM}}$ as a measure of economic development, where we assume that development increases with index score.

Table 2 shows some key descriptive statistics of economic development in Uganda. For the full sample, the mean of 37.14 and the median of 37.00 of PPI TM differ only marginally, and hence the distribution seems symmetric. For the areas 1 and 2, however, the median is more

\footnotetext{
${ }^{3}$ In case there were two heads of a household, for example when a family had a father and a mother, either would be accepted as an interviewee. Only one head of a household was interviewed.
} 
than 4 points lower than the mean causing the distribution to be positively skewed, which is due to a few highly developed households. No household scores the full hundred points, implying that no single household is fully developed in terms of the PPI ${ }^{\mathrm{TM}}$. Both the lowest and the highest economically developed households are reported in area 1, explaining the high standard deviation for this area. Figures 2 to 5 in Appendix B display the histograms of economic development for the full sample and for the three areas.

In addition to PPI ${ }^{\mathrm{TM}}$ scores, Table 2 shows the average poverty likelihood. This likelihood associates with the probability (in percentages) that a household is below the poverty line. ${ }^{4}$ Chen et al. (2008) assign poverty likelihoods to each 5-point range of PPI ${ }^{\mathrm{TM}}$; the average of these likelihoods is presented in Table 2. The likelihoods for the areas differ between $10 \%$ and $15 \%$ from the reported poverty levels, which can be explained by the fact that the poverty levels in Table 2 are given at the county level and not at the sub-county level. ${ }^{5}$ Of course, it may also be the case that Kenyan score card needs further modification to match the Ugandan situation. On the other hand, Chen et al. (2008) use 1997 survey data, and, more than 10 years later, these data might have become less applicable to calculate economic development.

\section{Telephone variables}

The aim of our study is to measure the effect of mobile telephone use of the head of the household $^{6}$ on the economic development of his/her household. "Telephone use" is classified into "basic telephone use" and "advanced telephone use". Public phone is assigned to the basic use category and incorporates both phone booths and pay phones, the latter being a telephone that can be used in exchange for a charge. ${ }^{7}$ About $40 \%$ of the Ugandan population uses a public phone on a regular basis (Gillwald and Stork, 2008). Basic telephone use also includes tradi-

\footnotetext{
${ }^{4}$ Chen et al. (2008) use the "national poverty line", which is equal to the expenditures needed for food and non-food basic needs.

${ }^{5}$ For area 1 , the urban areas of the Buikwe county have a relatively low poverty level of $18 \%$. However, the respondents in this area where from the town Nkokonjeru, which has poverty level $29 \%$. In area 3, the low poverty likelihood resulted from selecting respondents who, while living in rural areas, live close to the urban area of Kasese. Because detailed maps of area 2 are difficult to find, it is currently not possible to assign the correct poverty rates at sub county level.

${ }^{6}$ We use the variable " the number of mobile phone users" to measure the telephone use of the entire household.

${ }^{7}$ Five percent of the individuals in the data set offered their personal mobile phone for public use for a charge.
} 
tional use of mobile phone, which is both through voice (phone calls) and text (SMS). Uganda, with a population of more than 32 million, had close to 10 million mobile subscriptions in March 2010 (Ugandan Communications Commission, 2010). Mobile network coverage increased to 70\% in 2005 from $46 \%$ in 2003 (Telecommunications Union, 2007).

Advanced telephone use goes beyond traditional phone calls and SMS. Our study examines the applications of m-banking and mobile search. The provider MTN was the first to introduce m-banking in Uganda in March 2009, soon to be followed by Zain in June 2009. MTN already reported its millionth m-banking subscriber in May $2010 .^{8}$

Mobile search services offer SMS information on request, with or without a charge. Several mobile search services are present in Uganda. Zain Uganda, for example, provides SMS information on request and for a charge on topics such as financial news, sports and horoscope. Another example is Google SMS, which was launched in 2009 by MTN, Google and the Grameen Foundation. Google SMS offers, among others, free information on health and agriculture, which has been collected in cooperation with non-profit organizations.

Table 3 shows the user rates of both basic and advanced telephone services in our sample. It is important to note that a "mobile phone user" is defined as someone who owns a mobile phone. The mobile phone is more popular than the public phone, that is, $63 \%$ of the heads of households is a mobile phone user, while $43 \%$ is a public phone user, where we have 42 mobile phone users who also use public phones. $77 \%$ of households has at least one mobile phone using member. On average, each household has more than one mobile phone user (1.35).

Concerning advanced telephone use, the low user rates are striking, that is, only $12 \%$ for m-banking and only $5 \%$ for mobile search. These low percentages can perhaps be explained by the very recent introduction of both services. The currently small size of the samples of m-banking and mobile search users excludes advanced statistical analysis, and we suggest to collect more data for future research in this area.

Table 4 shows various descriptive statistics of variables measuring specifics of basic and

\footnotetext{
${ }^{8}$ See http://www.mtn.co.ug/About-MTN/News-Room/2010/May/MTN-MobileMoney-Customers-cros.aspx, last accessed on 27 August 2010.
} 
advanced telephone use, such as frequency, purpose and expenditure. The statistics are reported for subsamples of users. Figures 6 to 10 in Appendix B display histograms of economic development for each subsample. Mobile phone users make a phone call almost every day, whereas public phone users make phone calls about two days a week. A mobile phone is more frequently used for phone calls than for SMS. Public phone and mobile phone, both voice and text, are mostly used to contact friends and family. Less users have business reasons for the use of these services.

The histograms in Figures 12 and 13 in Appendix C show distributions of ownership duration and airtime expenditure that are positively skewed, explaining the high standard deviations relative to the mean and indicating potential outliers. The same observation is true for the categorical variables like public phone call frequency, number of networks and SMS frequency (Figures 11, 14 and 16 in Appendix C). Phone call frequency, however, is negatively skewed with many observations in the "daily" category (Figure 15).

Similar to public and mobile phone, m-banking is most often used to transfer to, or receive money from, friends and family members. On average, this service is used less than once a week and the amounts transferred range from $200 \mathrm{UGX}^{9}$ (0.07 EUR) to as much as 500000 UGX (173.98 EUR). Mobile search services are used more than once a week and sports is the most popular information category.

\section{Household characteristics}

Table 5 presents sample characteristics of users of public phone, mobile phone, m-banking and mobile search. ${ }^{10}$ Compared to the full sample, non-users are less economically developed, have

\footnotetext{
${ }^{9}$ UGX is an acronym for the 'Ugandan Shilling.' The EUR/UGX exchange rate was equal to 2873.85 on 12 March 2010.

${ }^{10}$ Compared to national data, the sample of this study is different in several aspects. The household size exceeds the Ugandan average of 4.7 persons (Uganda Bureau of Statistics, 2006c), and the sample urbanization rate is almost $4 \%$ higher than the rate of $12.3 \%$ for Uganda as a whole (Uganda Bureau of Statistics, 2006d). The average years of education is lower than the national average of 10 years (Central Intelligence Agency, 2009), while the literacy rate is more than $10 \%$ higher than the population average of less than $69 \%$ (Uganda Bureau of Statistics, 2006b). This discrepancy is caused by a high literacy rate in area 1 (see Table 9 in Appendix D). The proportion of farmers is lower than the national average of $71 \%$ (Uganda Bureau of Statistics, 2006a), caused by a high sample urbanization rate.
} 
a lower literacy rate and education level, and few of them live in urban areas, which in turn associates with the high proportion of farmers. Non-users tend to be seven years older than users and most of them are female. Illiteracy, which is linked to a lower education level and a higher age ${ }^{11}$ makes it more difficult to use a telephone.

Many of these observations on non-users also apply to public phone users, albeit to a lesser degree. Non-users have a lower economic development, education level and literacy rate than the average of the total sample. ${ }^{12}$

Mobile phone users, on the other hand, score five points above the sample average of economic development. Mobile search users and m-banking users score as much as eight points higher. Mobile search users' economic development shows more variation than that of other users. The high standard deviation is caused by the fact that the small mobile search sample reports PPI ${ }^{\mathrm{TM}}$ values as low as 19 and as high as 86 .

The literacy rate of mobile phone users is close to 1 . The literacy rate of mobile search users is equal to 1 , which is not unexpected. All users, with m-banking and mobile search in particular, have a higher education level than the sample mean. M-banking is more prevalent in rural areas, while mobile search is used more frequently in urban areas. The relatively high economic development, literacy and education level of advanced users correspond with the "early adopter" characteristics that Ivatury and Mas (2008) mention in relation to m-banking users.

The average age of users is about the same across the different types of users, but the standard deviation is around two years lower for advanced users. Apparently, advanced services have not made their way (yet) to the youngest and the oldest categories of basic users.

The bottom panel of Table 5 refers to the feeling of well-being of the heads of households. The interviewees answered the following three questions on a five-point Likert scale $(1=$ not at all, 5=extremely): "How important do you believe you are to others?"; "Do you believe

\footnotetext{
${ }^{11}$ The average education level and age of illiterates is 3.4 years and 44.2 years, respectively, whereas these values for literates are 9.0 and 38.1 .

${ }^{12}$ For public phone users who do not use a mobile phone, these results are more pronounced. With an education level of 6.51 years and literacy rate of 0.58 , this category of users is only slightly outperforming the non-users. In terms of PPI ${ }^{\mathrm{TM}}$, which is 28.14 on average, these users are even doing worse than non-users.
} 
you can accomplish in life what you want?"; and "Do you believe your children will succeed in education?" In general, interviewees gave fairly positive answers to all three questions. The correlation between economic development and the average of three well-being variables is 0.24 . Public phone users are scoring below average with regards to well-being, and mobile phone users score above average. Mobile search users are scoring particularly high, rating around 0.5 points above the average for all three questions. Table 9 in Appendix D presents descriptive statistics for urban households and for households from the three different geographic areas.

In sum, we see that mobile search and m-banking correlate positively with economic prosperity and with feelings of well-being. Unfortunately, we do not have enough data to formally test these correlations, also as the econometric model should allow for two-way causality. Hence, in the next section we exclusively focus on the effects on mobile phone use.

\section{Methodology and results}

So far, we discussed the link between higher levels of economic development and mobile phone, m-banking and mobile search users. The nature of this link is uncertain, however. Indeed, more economic development may also facilitate the adoption of these new products. Hence, when we zoom in on the potential increase of economic development, we must take into account the possibility of a simultaneous relation.

\section{IV estimation}

Basically, we consider the regression model

$$
y=X \beta+\epsilon,
$$

where $y$ is a measure of economic development, $X$ is an $n \times k$ matrix which includes an intercept, telephone variables, and other variables, $\beta$ is a $k \times 1$ vector of coefficients and $\epsilon$ is a $n \times 1$ vector with errors. Simultaneity implies regressors can be endogenous, which in econometric language means that

$$
E\left(X^{\prime} \epsilon\right) \neq 0,
$$


where $E$ is the expectations operator. Endogeneity leads to inconsistent and biased parameter estimates, which is a common problem in the literature on economic development, see Easterly and Levine (2002). ${ }^{13}$ Hence, we resort to Instrumental Variables (IV) estimation to obtain consistent parameter estimates.

Assume that $X$ consists of $X_{1}$ and $X_{2}$, which associate with endogenous and exogenous regressors, respectively. We regress each column of $X_{1}$ on instruments captured in $Z$, which are exogenous variables that are sufficiently correlated with the possibly endogenous regressors, which in our case concerns telephone activity. Formally,

$$
x_{1 j}=Z \gamma_{j}+\eta
$$

for each $j=1, \ldots, k$. The $n \times 1$ vector $x_{1 j}$ includes observations for the $j^{\text {th }}$ possibly endogenous regressor. $Z$ is an $n \times m$ matrix of instruments, $\gamma_{j}$ an $m \times 1$ vector of coefficients for the $j^{\text {th }}$ regressor and $\eta$ is an $n \times 1$ vector with errors. Using (3) we calculate

$$
\hat{x}_{1 j}=Z \hat{\gamma}_{j}
$$

where $\hat{\gamma}_{j}$ is the estimated coefficient vector.

Next, the estimated regressors from Equation 4 are used as explanatory variables in a regression with dependent variable $y$ and exogenous variables $X_{2}$, that is,

$$
y=\hat{X}_{1} \beta_{1}+X_{2} \beta_{2}+\epsilon
$$

where $\hat{X}_{1}$ is a $n \times k$ matrix with columns $\hat{x}_{1 j}, X_{2}$ is an $n \times p$ matrix (including an intercept), $\beta_{1}$ and $\beta_{2}$ are $k \times 1$ and $p \times 1$ vectors of coefficients respectively, and $\epsilon$ is an $n \times 1$ error vector.

All non-binary variables - except for variables that measure proportions - are $\log (1+x)$ transformed, thereby reducing skewness and heteroskedasticity. We add a 1 as some variables can attain the value of zero.

\footnotetext{
${ }^{13}$ Duncombe and Boateng (2009) mention the problem of endogeneity in relation to mobile phones and financial services: "there is a problem of attribution and how to disentangle the effects of mobile phones from other contributory factors and the related issue of endogeneity."
} 
Vector $y$ in this study consists of observations on economic development described in Section 3. The regressors $x_{1 j}$ are measures of telephone use. The exogenous regressors and other instrumental variables in the matrix $Z$ are household characteristics and public phone variables. Individuals with missing values are deleted from the data set. ${ }^{14}$

Regression parameters are estimated for all possible combinations of instruments. We test for endogeneity using the Durbin statistic (Durbin, 1954) and for validity using the Sargan statistic (Sargan, 1958). Even though instruments can be valid, the variables can be insufficiently correlated with the endogenous regressors. This "weakness" of instruments is indicated by a low partial $R^{2}$ for (3), meaning that the instruments have low explanatory power for an individual endogenous regressor. Weak instruments cause relatively large error variances for (5). We report the regression results for the instrument set with the highest first stage fit, which is defined as the set with the highest $\mathrm{F}$ statistic in the first stage regression. To ensure the maximum bias in IV does not exceed the bias of OLS with more than $10 \%$, we use the rule of thumb of $F>10$. However, we can relax this rule of thumb to $F>5$ if we are willing to accept a somewhat higher bias (Cameron and Trivedi, 2005).

\section{Results}

Table 6 displays the highest fit IV results for three different regressions, each with a constant and one mobile phone variable. Inspired by Narayan and Pritchett (1997), we use household size, years of education of the head of household and being a farmer as control variables. In addition, a dummy for area 2 is added, as there is a large difference between the economic development in this area and the other two.

As can be seen from the estimation results, mobile phone use, regardless of how it is measured, has a significant positive effect at the $5 \%$ or $1 \%$ confidence level. In the first two regressions, mobile phone use is measured with binary variables. The variables are equal to 1 if the head of household or at least one household member is mobile phone user in regression (a) and

\footnotetext{
${ }^{14}$ The most common reasons for missing values were interviewer notation errors, such as unreadable handwriting. In addition, 3 interviewees did not answer the well-being questions.
} 
(b) respectively and otherwise, the variables are equal to zero. The impact of use of at least one household member is larger than the impact of the head of household's telephone use, that is, 0.89 as opposed to 0.62. Apparently, household members, who do not classify as head of a household, influence development with mobile phone use. An additional explanation for the higher coefficient is the importance of the number of users, as the mobile phone use variable at the household level is equal to 1 for one user as well as for multiple users in a household. This last notion is confirmed by the results of regression (c) in Table 6. In case the proportion of users in a household increases with 50\%, the development increases with $1 \%$. Of the control variables, only household size and the area 2 dummy have (close to) significant coefficients.

Table 10 in Appendix E displays the instrument set and selected instruments. Table 6 reports that we can reject the null of exogeneity of the mobile phone variable(s) in two of the three regressions (at a 10\% level). In all regressions where the validity of the instruments could be tested the null of exogenous instruments cannot be rejected.

Besides validity, we are also interested in the strength of the instruments selected. Table 6 reports the F statistic for the first stage regression. For regression (a) this statistic is higher than 10 and for (b) and (c) it is higher than 5, indicating that the bias due to weak instruments is acceptable. Even though the instruments are potentially weak, we do not obtain disproportionately large standard errors.

\section{Conclusion}

Mobile telephony has the power to enable individuals to efficiently obtain information both for personal and for professional purposes. This study confirms that mobile phone use has a positive impact on economic development, also at the individual household level.

\section{Implications}

Our conclusion on mobile phones have important policy implications. For example, funds could be aimed at mobile phone accessibility. The results in our study show that it is mainly important that individuals get access to mobile phones. It might be beneficial to encourage the use of $\mathrm{m}$ - 
banking and mobile search. That poor people are not usually early adopters of technology can be explained by personal experience (they are likely to have had less exposure to technology and have less access to information about new offerings) as well as the fact that they are less attractive to providers. This makes the task much harder for governments and donors who are targeting poor people with financial services. Government programs in India, Russia, Malawi, South Africa, and Brazil distribute social protection payments to customers through branchless banking channels. These have been found successful at opening bank accounts for millions of poor customers in some cases (notably Brazil), but have not led to regular use of those accounts to spread expenditures over time. Balances tend to be withdrawn in full as soon as payments are received. More research is needed on how poor and excluded clients view their relationship with banking agents and their willingness to trust providers (Ivatury and Mas, 2008).

In accordance with statements by Ivatury and Mas (2008) about m-banking users in South Africa, advanced telephone users have the "early adopter" characteristics of high economic development, literacy and education level. First, transaction costs are high and user rates are low at this early stage. Over time, with lower costs and higher user rates,${ }^{15}$ developmental impact will be larger and the negative effect of frequency is expected to fade. Also, longer term effects of m-banking use will have rooted, reaping additional developmental benefits. Future research will gain more insight from larger data sets and will be able to draw more sound conclusions on the impact of use.

\section{Discussion}

Points of improvement do not merely concern explanatory variables. The dependent variable of economic development also requires additional investigation. First of all, this study used Kenya's PPI ${ }^{\mathrm{TM}}$ scorecard, which might be suboptimal. Currently (2011), the Grameen Foundation is in the process of developing a scorecard for Uganda. It would be valuable to compare the results for the Ugandan scorecard with our results, to assess to applicability of the scorecard in

\footnotetext{
${ }^{15}$ High user rates have a positive effect on development through the so-called "network effect," a common term in ICT literature. The network effect implies that a service's benefits increase with the number of users.
} 
Uganda. Secondly, further analysis is required to confirm the validity of the PPI ${ }^{\mathrm{TM}}$ in statistical analysis. Thirdly, the PPI ${ }^{\mathrm{TM}}$ measures economic development at the household level, while many regressors are measured at the level of the head of household. Further data collection should therefore include more information on the household as a whole. 


\section{References}

Abraham, R. (2007). Mobile phones and economic development: Evidence from the fishing industry in India. Information Technologies and International Development, $\mathbf{4}$, number 1, $5-17$.

Aker, J. (2008). Does Digital Divide or Provide? The Impact of Cell Phones on Grain Markets in Niger. Working Paper 154. Center for Global Development.

Bayes, A., von Braun, J. and Akhter, R. (1999). Village pay phones and poverty reduction: Insights from a Grameen Bank initiative in Bangladesh. Discussion Paper 8. Bonn: Centre for Development Research, Universitat Bonn.

Cameron, A.C. and Trivedi, P.K. (2005). Microeconometrics: Methods and Applications, 7 edn. New York, NY: Cambridge University Press.

Central Intelligence Agency (2009). The World Factbook 2009. Technical Report. Washington, DC: CIA.

Chen, S., Schreiner, M. and Woller, G. (2008). Progress out of Poverty Index ${ }^{\mathrm{TM}}$ : A Simple Poverty Scorecard for Kenya. Technical Report. Grameen Foundation.

Coyle, D. (2007). Overview. Policy Paper 6, 2-5. Vodafone Group.

Cragg, J.G. and Donald, S.G. (1993). Testing Identiability and Specication in Instrumental Variable Models. Econometric Theory, 9, 222-240.

Donner, J. (2008). Research Approaches to Mobile Use in the Developing World: A Review of the Literature. The Information Society, 24, 140-159.

Duncombe, R. and Boateng, R. (2009). Mobile Phones and Financial Services in Developing Countries: a review of concepts, methods, issues, evidence and future research directions. Third World Quarterly, 30, number 7, 1237-1258.

Durbin, J. (1954). Errors in variables. Review of the International Statistical Institute, 22, $23-32$.

Easterly, W. and Levine, R. (2002). Tropics, germs and crops: how endowments influence economic development. Journal of Monetary Economics, 50, 3-39.

Eggleston, K. N., Jensen, R. and Zeckhauser, R. (2002). Information and Communication Technologies, Markets and Economic Development. Discussion Paper 0203. Department of Economics, Tufts University.

Emwanu, T., Okwi, P. Okiira, Hoogeveen, J.G., Kristjanson, P. and Henninger, N. (2007). Nature, Distribution and Evolution of Poverty and Inequality in Uganda. Technical Report. International Livestock Research Institute.

Gillwald, A. and Stork, C. (2008). Towards Evidence-based ICT Policy and Regulation: ICT access and usage in Africa. Technical Report. Research ICT Africa.

Hardy, A. P. (1980). The role of the telephone in economic development. Telecommunications Policy, 4, number 4, $278-286$. 
Ivatury, G. and Mas, I. (2008). The early experience with branchless banking. Technical Report. Washington DC: Consultative group to assist the poor (CGAP) and the United Nations Foundation.

Ivatury, G. and Pickens, M. (2002). Mobile phone banking and low-income countries: Evidence from South Africa. International Journal of Retail \& Distribution Management, 30, number 6, 331-339.

Jensen, R. (2007). The Digital Provide: Information (Technology), Market Performance, and Welfare in the South Indian Fisheries Sector. The Quarterly Journal of Economics, 122, number 3, 879-924.

Jones, M., Buchanan, G., Harpe, R. and Xech, P. (2007). Questions not answers: a novel mobile search technique. In CHI '07: Proceedings of the SIGCHI conference on Human factors in computing systems, New York, NY, USA, pp. 155-158. ACM.

Kamvar, M. and Baluja, S. (2006). A large scale study of wireless search behavior: Google mobile search. In CHI '06: Proceedings of the SIGCHI conference on Human Factors in computing systems, New York, NY, USA, pp. 701-709. ACM.

Kathuria, R., Uppal, M. and Mamta (2009). An econometric analysis of the impact of mobile. Policy Paper 9, 5-20. Vodafone Group.

Laforet, S. and Li, X. (2005). Consumers attitudes towards online and mobile banking in China. International Journal of Bank Marketing, 23, number 5, 362-380.

Mittal, S., Gandhi, S. and Tripathi, G. (2009). The impact of mobiles on agricultural productivity. Policy Paper 9, 21-33. Vodafone Group.

Muto, M. and Yamano, T. (2009). The Impact of Mobile Phone Coverage Expansion on Market Participation: Panel Data Evidence from Uganda. World Development, 37, number 12, 18871896.

Narayan and Pritchett (1997). Cents and Sensibility:Household Income and Social Capital in Rural Tanzania. Technical Report. World Bank.

Porteous, D. (2007). Just how transformational is m-banking? Technical Report. FinMark Trust.

Sargan, J.D. (1958). The estimation of economic relationships using instrumental variables. Econometrica, 26, 339-415.

Scott, N., Batchelor, S., Ridley, J. and Jorgensen, B. (2004). The impact of mobile phones in Africa. Technical Report. Commission for Africa.

Stigler, G. J. (1961). The economics of information. The Journal of Political Economy, 5, number 4, 213-225.

Stock, J.H. and Yogo, M. (2005). Testing for weak instruments in linear IV regression. In Identification and Inference for Econometric Models: Essays in Honor of Thomas Rothenberg, New York, NY (eds D. Andrews and J. Stock), pp. 80-108. Cambridge University Press. 
Telecommunications Union, International (2007). Yearbook of statistics: Telecommunication services 1996-2005. Technical Report. ITU.

The Economist (2009a). Eureka Moments. Published on 24 September, 2009. Retrieved on 21 July, 2010, from http://www.economist.com/node/14483872.

The Economist (2009b). The Power of Mobile Money. Published on 24 September, 2009. Retrieved on 20 July, 2010, from http://www.economist.com/node/14505519.

The Economist (2010). Out of thin air. Published on 10 June, 2010. Retrieved on 20 July, 2010, http://www.economist.com/node/16319635.

Uganda Bureau of Statistics (2006a). The 2002 Uganda Population and Housing Census, Economic Characteristics. Technical Report. Kampala: UBoS.

Uganda Bureau of Statistics (2006b). The 2002 Uganda Population and Housing Census, Education and Literacy. Technical Report. Kampala: UBoS.

Uganda Bureau of Statistics (2006c). The 2002 Uganda Population and Housing Census, Household Characteristics. Technical Report. Kampala: UBoS.

Uganda Bureau of Statistics (2006d). The 2002 Uganda Population and Housing Census, Population Size and Distribution. Technical Report. Kampala: UBoS.

Ugandan Communications Commission (2010). Status of the Communications Market - March 2010. Technical Report. Kampala: UCC.

Waverman, L., Meschi, M. and Fuss, M. (2005). The impact of telecoms on economic growth in developing nations. Policy Paper 2, 10-23. Vodafone Group. 


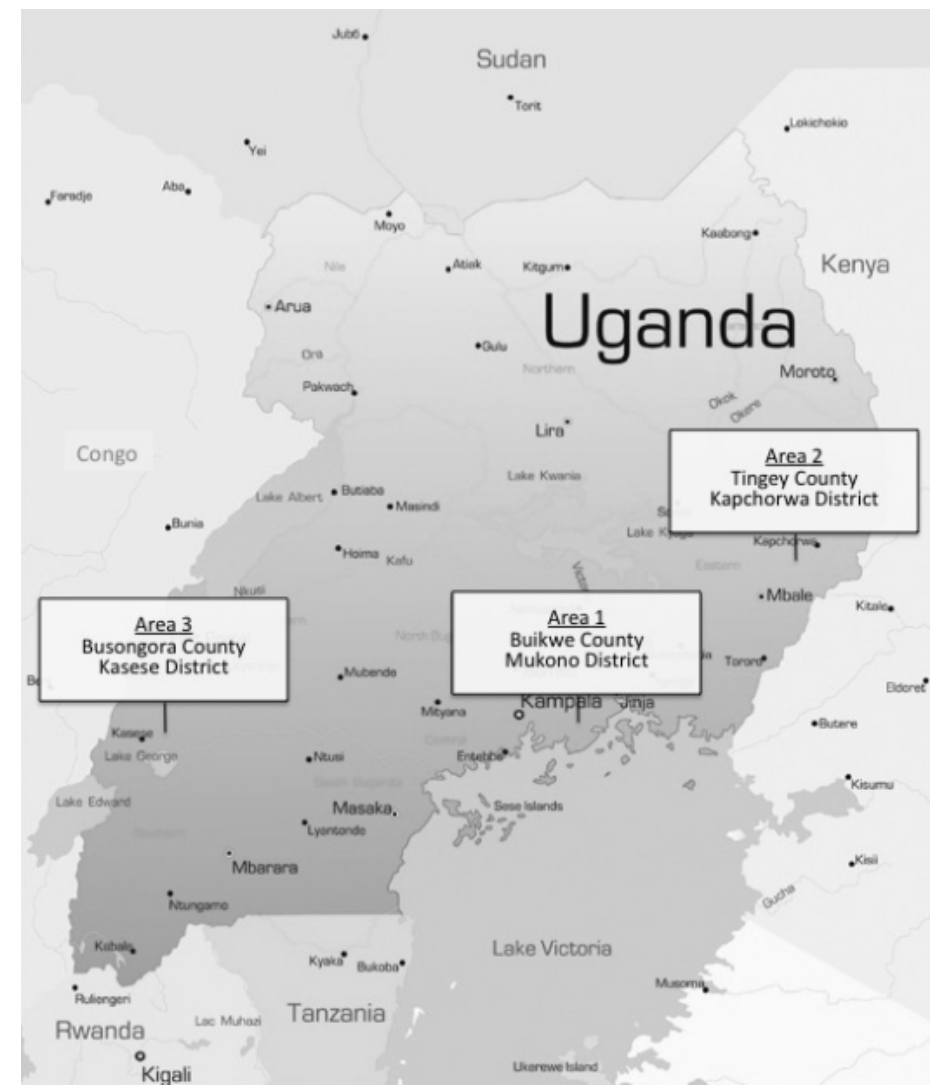

Figure 1: The three geographical survey areas 
Table 1: Economic development scorecard

\begin{tabular}{llc}
\hline \hline Question & Answer & Points \\
\hline \hline 1. How many household members & A: 3 or more & 0 \\
are aged 25 or younger? & B: 0, 1 or 2 & 8 \\
\hline 2. How many household members & A: Not all & 0 \\
aged 6 to 17 are currently attending school? & B: All & 8 \\
& C: No children aged 6 to 17 & 21 \\
\hline 3 What is the material of the walls of & A: Mud/cow dung/grass/sticks & 0 \\
the house? & B: Other & 5 \\
\hline 4. What kind of toilet facility does & A: Other & 0 \\
your household use? & B: Flush to sewer; flush to septic tank; & 2 \\
& pan/bucket; covered pit latrine; & \\
& or ventilation improved pit latrine & 0 \\
\hline 5. Does the household own a TV? & A: No & 16 \\
\hline 6. Does the household own a sofa? & B: Yes & 0 \\
& A: No & 14 \\
\hline 7. Does the household own a stove? & B: Yes & 0 \\
& A: No & 12 \\
\hline 8. Does the household own a radio? & B: Yes & 0 \\
& A: No & 8 \\
\hline 9. Does the household own a bicycle? & B: Yes & A: No \\
& B: Yes & 5 \\
\hline 10. How many head of cattle are & A: None or unknown & 0 \\
owned by the household currently? & B: 1 or more & 9 \\
\hline \hline
\end{tabular}

Note: This table presents the scorecard used to calculate the Progress out of Poverty Index ${ }^{\mathrm{TM}}$ (PPI ${ }^{\mathrm{TM}}$ ) of a household. The PPI ${ }^{\mathrm{TM}}$ is the sum of the scores of the answers to all ten questions in the table. The scorecard is a reproduction of the scorecard in Chen et al. (2008). 
Table 2: Descriptive statistics of economic development for the full sample and for the three geographic areas

\begin{tabular}{lcccc}
\hline \hline & Total & Area 1 & Area 2 & Area 3 \\
\hline \hline & & & & \\
Mean & 37.14 & 40.38 & 31.69 & 40.92 \\
Median & 37.00 & 37.00 & 27.00 & 42.00 \\
Maximum & 86.00 & 86.00 & 67.00 & 67.00 \\
Minimum & 9.00 & 9.00 & 10.00 & 10.00 \\
Std. Dev. & 15.87 & 17.83 & 14.40 & 13.96 \\
Observations & 196 & 56 & 77 & 63 \\
& & & & \\
Average poverty likelihood (\%) & 35.98 & 35.62 & 44.61 & 35.13 \\
County poverty level (\%) & 32.31 & 22.60 & 29.00 & 45.00 \\
& & & & \\
\hline
\end{tabular}

Note: This table presents descriptive statistics of economic development for the total sample and for the three separate geographic areas (See map in Figure 1). In addition, the table displays the average poverty likelihoods. Each household is assigned a poverty likelihood based on the PPI ${ }^{\mathrm{TM}}$ score using results in Chen et al. (2008) and the average poverty likelihood is the mean of these values. The last row represents the county poverty levels as measured by Emwanu et al. (2007). The poverty level for area 1, which includes both rural and urban households, is a weighted average of the urban and rural rate. Areas 2 and 3 include only rural areas. Urban/rural areas are classified in accordance with Emwanu et al. (2007). Table 9 in Appendix D shows the proportion of urban households for each area. 
Table 3: Basic and advanced user rates

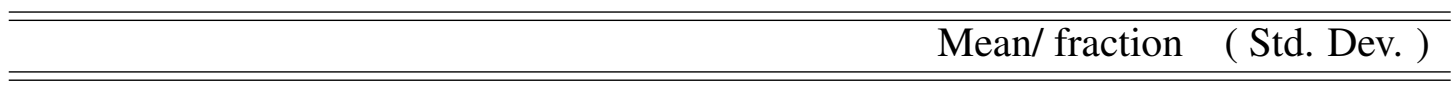

\section{Basic use}

Public phone use $(0=$ no, $1=$ yes $)$

Mobile phone use, head of household ( $0=$ no, $1=y e s)$

Mobile phone use, household ( $0=$ no, $1=$ yes)

0.77

Users in household

\section{Advanced use}

M-banking use $(0=$ no, $1=$ yes $)$

0.12

Mobile search use $(0=$ no, $1=$ yes $)$

0.05

Note: This table summarizes user rates for the full sample giving the mean/fraction (and standard deviation in parentheses). All variables are measured at the head of the household level, except for one mobile phone use variable and the number of users in the household. Mobile phone use at the household level measures whether or not at least one member uses a mobile phone. A "mobile phone user" is defined as someone who owns a mobile phone. 
Table 4: Descriptive statistics of basic and advanced telephone for subsamples of users

\begin{tabular}{l}
\hline \hline Mean/ fraction ( Std. Dev. ) \\
\hline \hline
\end{tabular}

\section{Basic use - public phone (85 obs)}

Phone call frequency (days a week)

1.67

Business phone calls $(0=$ no, $1=$ yes $) \quad 0.30$

Friends/family phone calls $(0=$ no, $1=$ yes $) \quad 0.90$

\section{Basic use - mobile phone (125 obs)}

Ownership duration (months) 49.33

Airtime expenditure (10000 UGX per month) $\quad 2.21$

Number of networks used $\quad 1.26$

Phone call frequency (days a week) $\quad 6.09$

SMS frequency (days a week) 1.51

Business phone calls $(0=$ no, $1=$ yes $)$

0.59

Friends/family phone calls $(0=$ no, $1=$ yes $) \quad 0.90$

Business SMS ( $0=$ no, $1=$ yes $) \quad 0.25$

Friends/family SMS ( $0=$ no, $1=$ yes $) \quad 0.50$

\section{Advanced use - m-banking (24 obs)}

Frequency (days a week) $\quad 0.70$

Average transaction $\quad 8.29$

$(0.54)$

Business transactions $(0=$ no, $1=$ yes $) \quad 0.25$

Friends/family transactions $(0=$ no, $1=$ yes $) \quad 0.63$

\section{Advanced use - mobile search (10 obs)}

Frequency (Days a week) $\quad 2.46$

Agriculture information $(0=$ no, $1=y e s) \quad 0.10$

Health information $(0=$ no, $1=$ yes $) \quad 0.10$

Sports information $(0=$ no, $1=$ yes $) \quad 0.50$

Trade information $(0=$ no, $1=$ yes $) \quad 0.10$

Weather information $(0=$ no, $1=$ yes $) \quad 0.00$

Note: This table shows the variables used to measure mobile phone, public phone, m-banking and mobile search use. The table presents a variable's mean or fraction (and standard deviation in parentheses) for the subsample of users of the relevant service. All variables are measured at the level of the head of the household. The acronym 'UGX' denotes Ugandan Shilling. The EUR/UGX exchange rate was equal to 2873.85 on 12 March 2010. A "mobile phone user" is defined as someone who owns a mobile phone. 


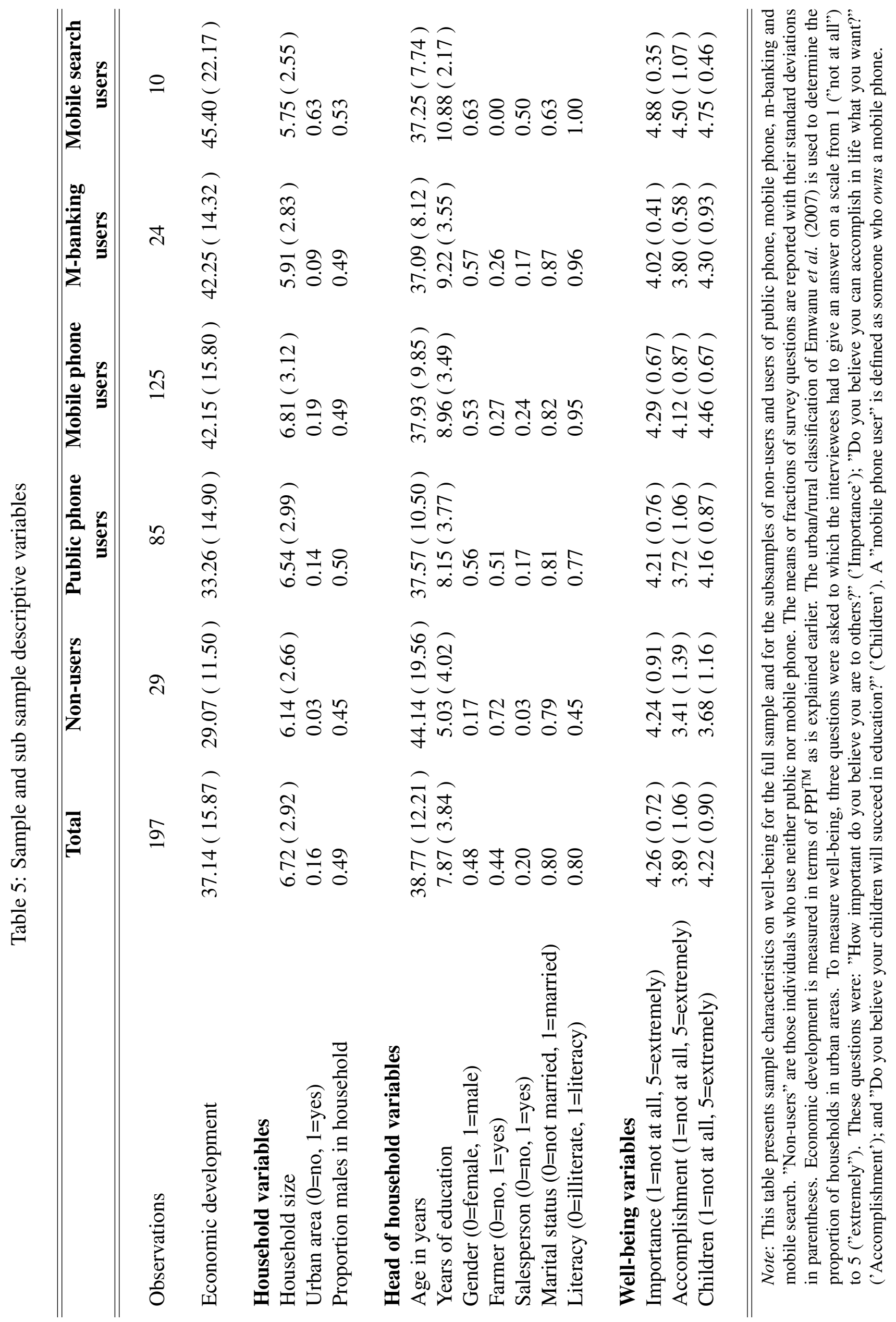


Table 6: Highest first stage fit IV estimates of the effects of mobile telephone use on economic development (full sample)

\begin{tabular}{lccc}
\hline \hline & (a) & (b) & $(\mathrm{c})$ \\
\hline Constant & $3.451^{* * *}$ & $3.097^{* * *}$ & $2.489^{* * *}$ \\
& $(0.209)$ & $(0.302)$ & $(0.543)$ \\
Household size & $-0.158^{* *}$ & $-0.195^{* * *}$ & 0.326 \\
& $(0.068)$ & $(0.072)$ & $(0.201)$ \\
Education, head of household (years) & -0.007 & 0.044 & 0.009 \\
& $(0.073)$ & $(0.065)$ & $(0.068)$ \\
Farmer $(0=$ no, 1=yes) & -0.095 & -0.011 & -0.003 \\
& $(0.085)$ & $(0.107)$ & $(0.123)$ \\
Area 2 (0=no, 1=yes) & & & \\
& 0.005 & -0.030 & $-0.139^{*}$ \\
& $(0.105)$ & $(0.100)$ & $(0.073)$
\end{tabular}

Mp use, head of household ( $0=$ no, $1=$ yes $) \quad 0.618^{* * *}$

Mp use, household ( $0=$ no, $1=$ yes $)$

Proportion mp users in household

\begin{tabular}{lccc} 
Observations & 167 & 167 & 191 \\
R-squared & 0.103 & 0.0692 & 0.143 \\
Adjusted R-squared & 0.0753 & 0.0403 & 0.120 \\
Durbin statistic & 4.904 & 3.825 & 2.320 \\
Durbin p-value & 0.0268 & 0.0505 & 0.128 \\
Sargan statistic & 1.373 & 2.061 &. \\
Sargan p-value & 0.241 & 0.151 &. \\
F statistic & 14.67 & 7.231 & 7.040 \\
R-squared & 0.155 & 0.083 & 0.037 \\
\hline \hline
\end{tabular}

Note: This table presents the highest fit regression results for basic telephone use for the full sample of heads of household. The parameters are estimated with the method of Instrumental Variables (IV). The highest fit is defined as the highest F statistic of the first stage in IV estimation, the estimation of Equation 3. The dependent variable is economic development of the household. Standard errors are in parentheses. Three asterisks indicate significance at the 0.01 level; two asterisks indicate significance at the 0.05 level; one asterisk indicates significance at the 0.10 level. A "mobile phone user" is defined as someone who owns a mobile phone. The Durbin test has the null of exogenous regressors and the Sargan test has the null of exogenous instruments. 


\section{Appendix A: List of variables}

Note: This table below consists of the description of variables used in this study. The short name, description, encodement and type are displayed for each variable. The following abbreviations are used in the first column: "pp" stands for "public phone", "mp" for "mobile phone", "mb" for "m-banking" and "ms" for mobile search. The ISCO classification for occupations is presented in the annex of the 2008 Resolution Concerning Updating the International Standard Classification of Occupations of the International Labor Organization. 


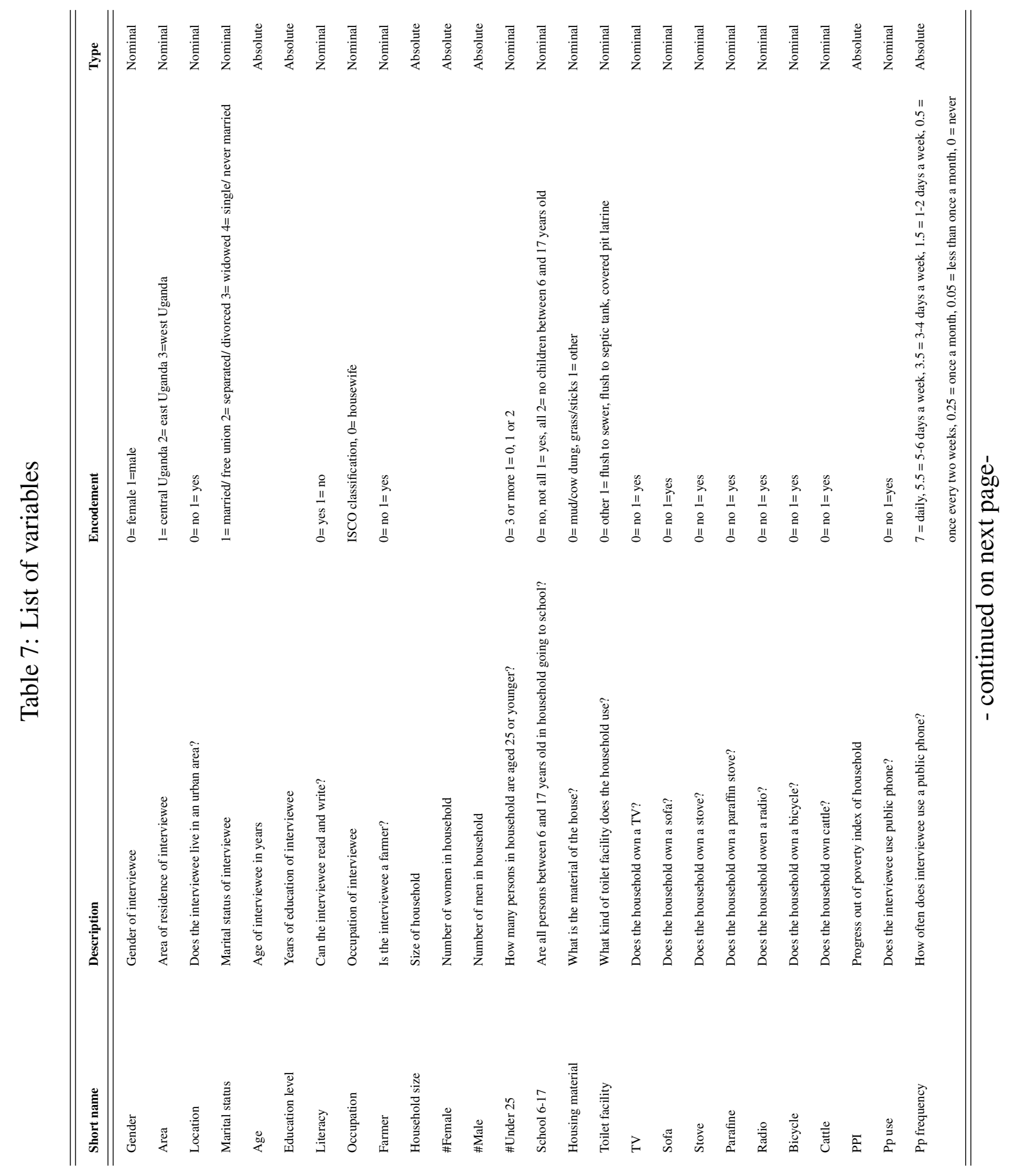




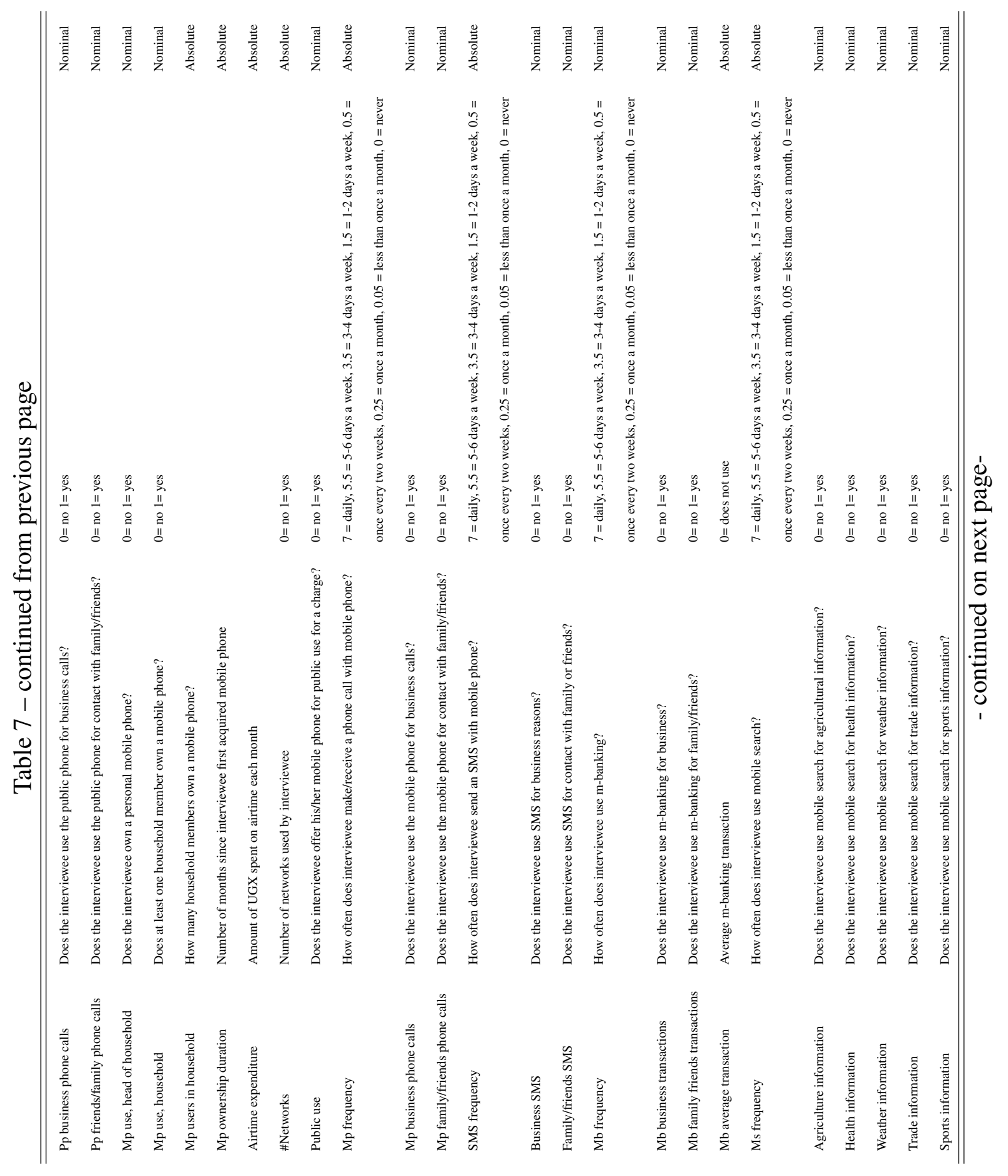




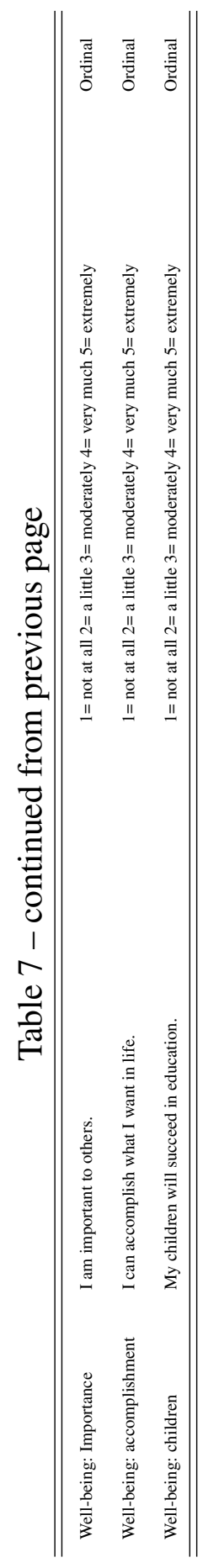




\section{Appendix B: Histograms - economic development}

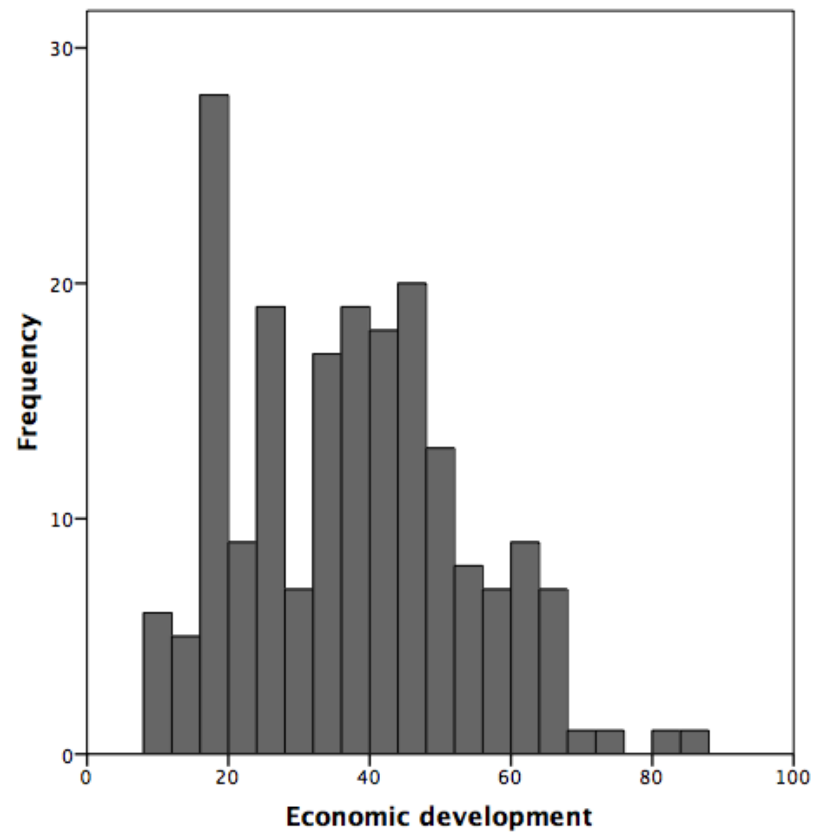

Figure 2: Histogram of economic development, as measured by PPI ${ }^{\mathrm{TM}}$, for the full sample. 


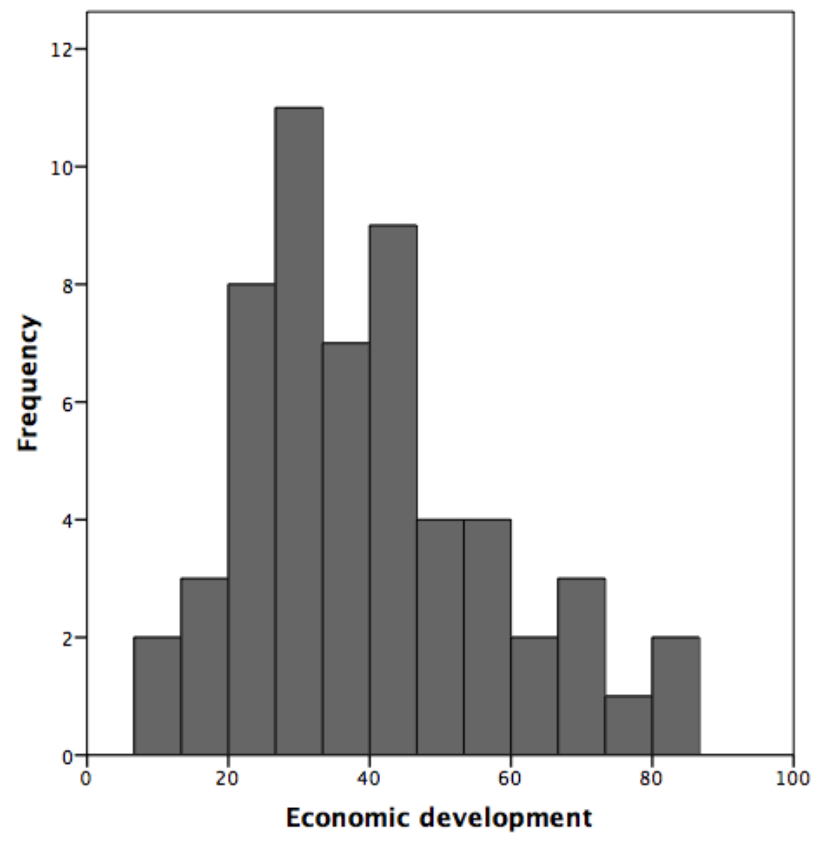

Figure 3: Histogram of economic development, as measured by PPI ${ }^{\mathrm{TM}}$, for area 1.

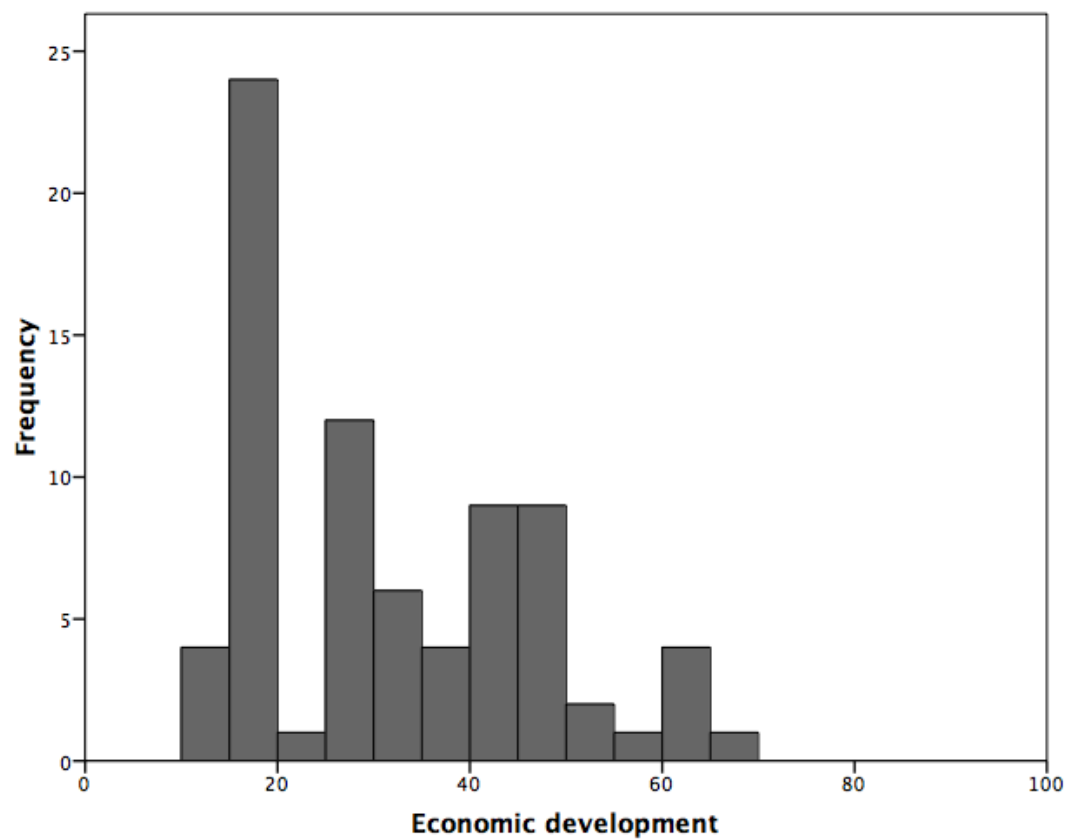

Figure 4: Histogram of economic development, as measured by PPI ${ }^{\mathrm{TM}}$, for area 2. 


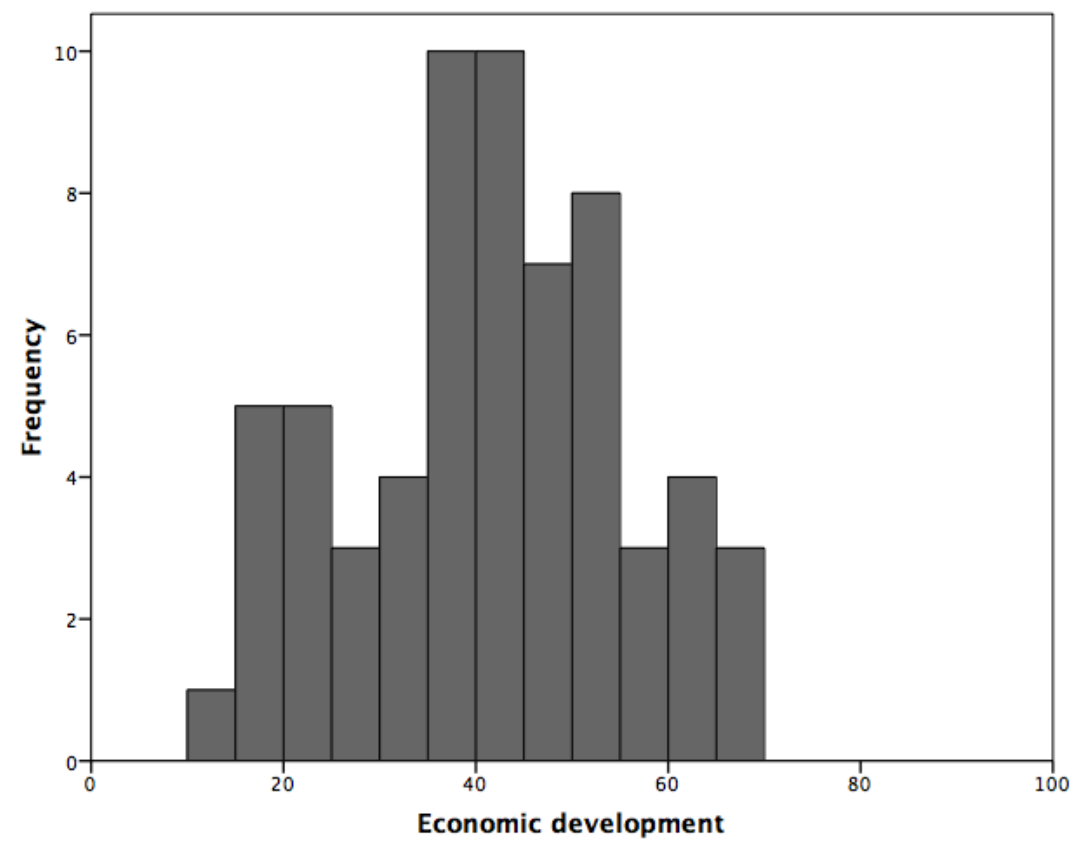

Figure 5: Histogram of economic development, as measured by PPI ${ }^{\mathrm{TM}}$, for area 3.

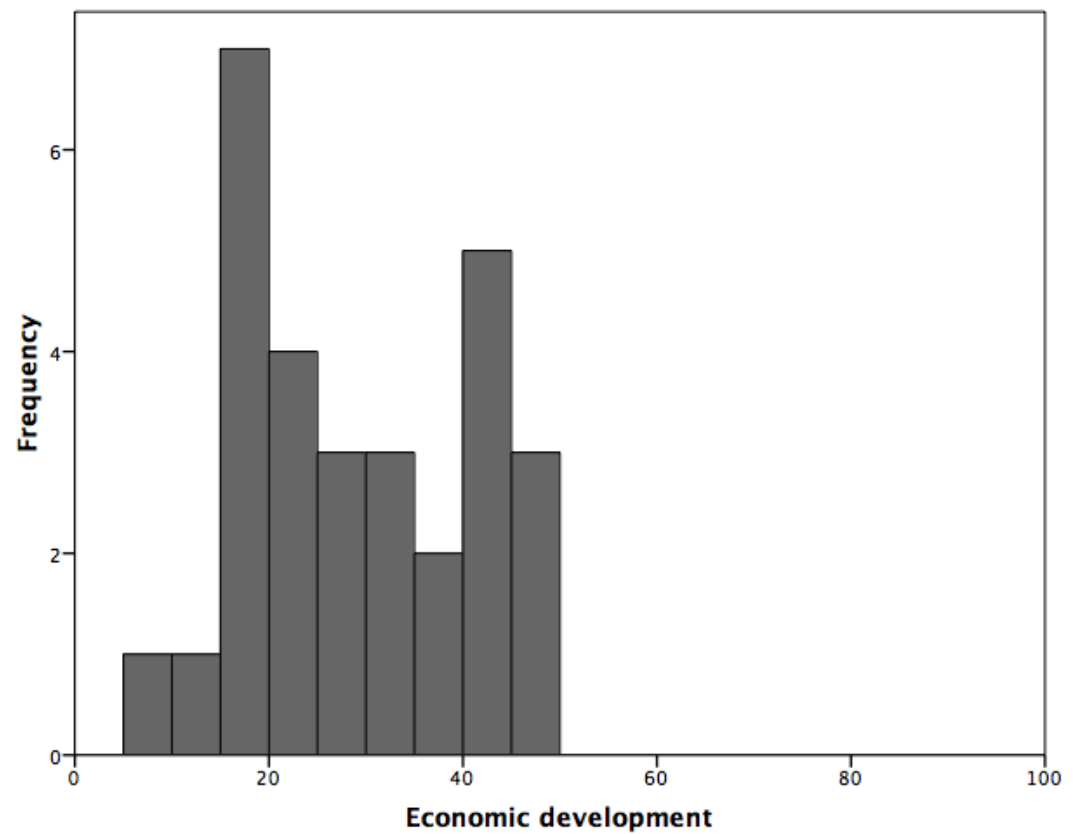

Figure 6: Histogram of economic development, as measured by PPI ${ }^{\mathrm{TM}}$, for non-users. 


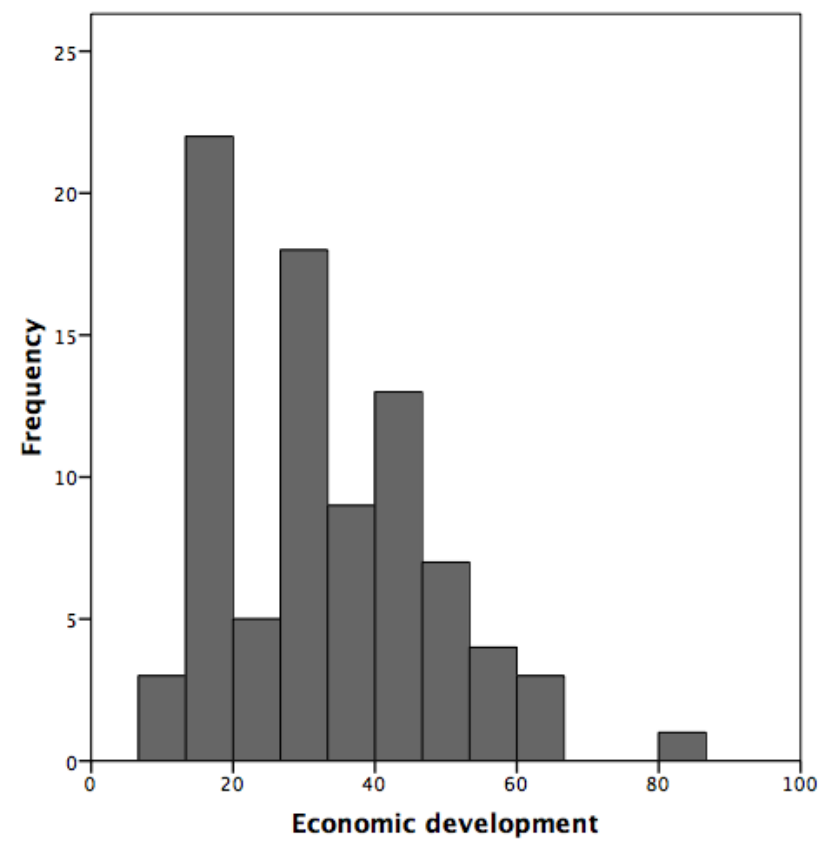

Figure 7: Histogram of economic development, as measured by PPI ${ }^{\mathrm{TM}}$, for public phone users.

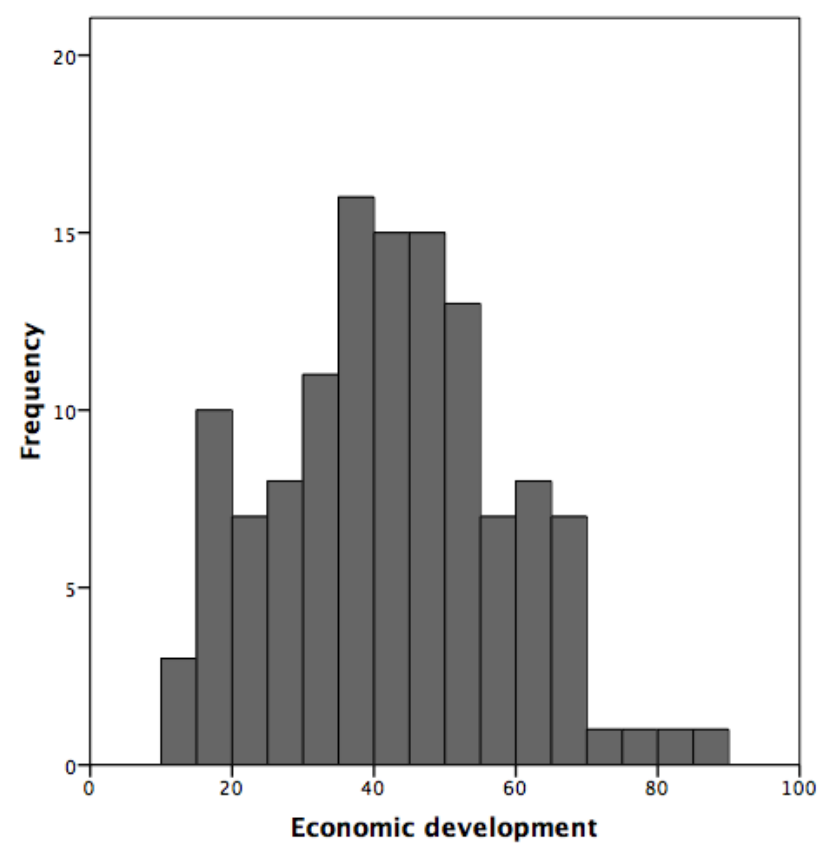

Figure 8: Histogram of economic development, as measured by PPI ${ }^{\mathrm{TM}}$, for mobile phone users. 


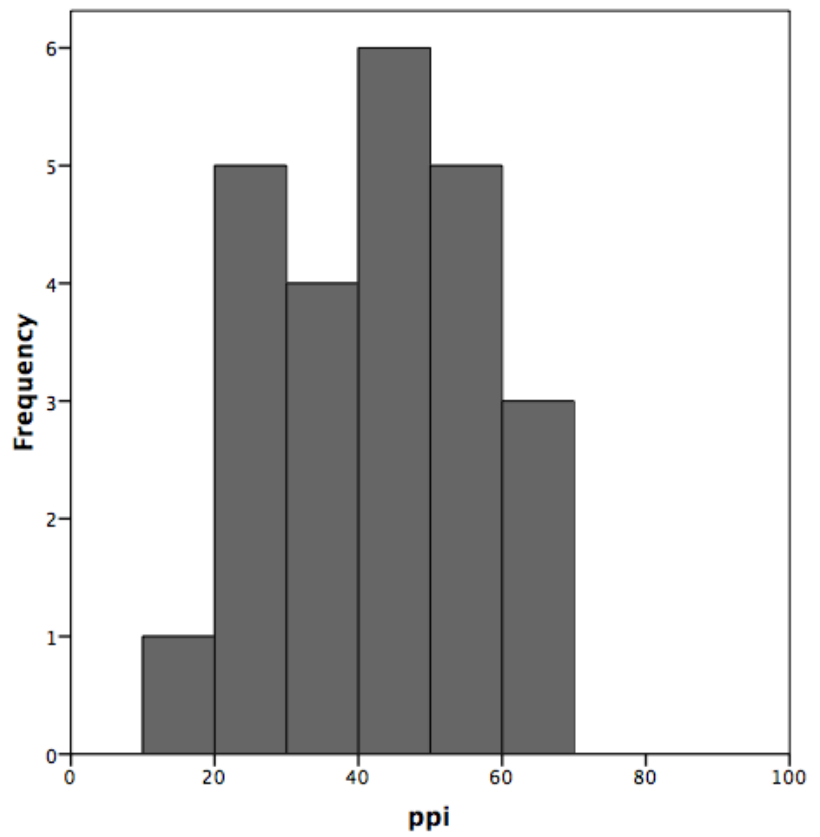

Figure 9: Histogram of economic development, as measured by PPI ${ }^{\mathrm{TM}}$, for m-banking users.

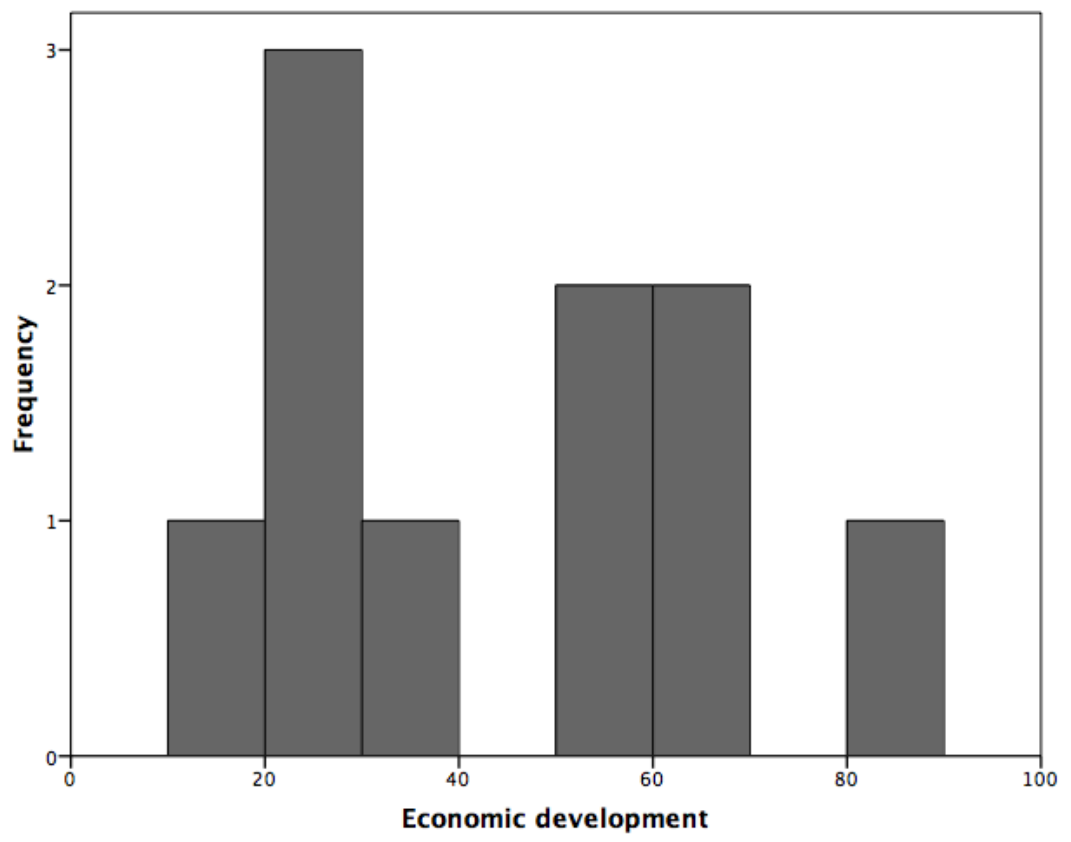

Figure 10: Histogram of economic development, as measured by PPI ${ }^{\mathrm{TM}}$, for mobile search users. 


\section{Appendix C: Histograms - telephone use}

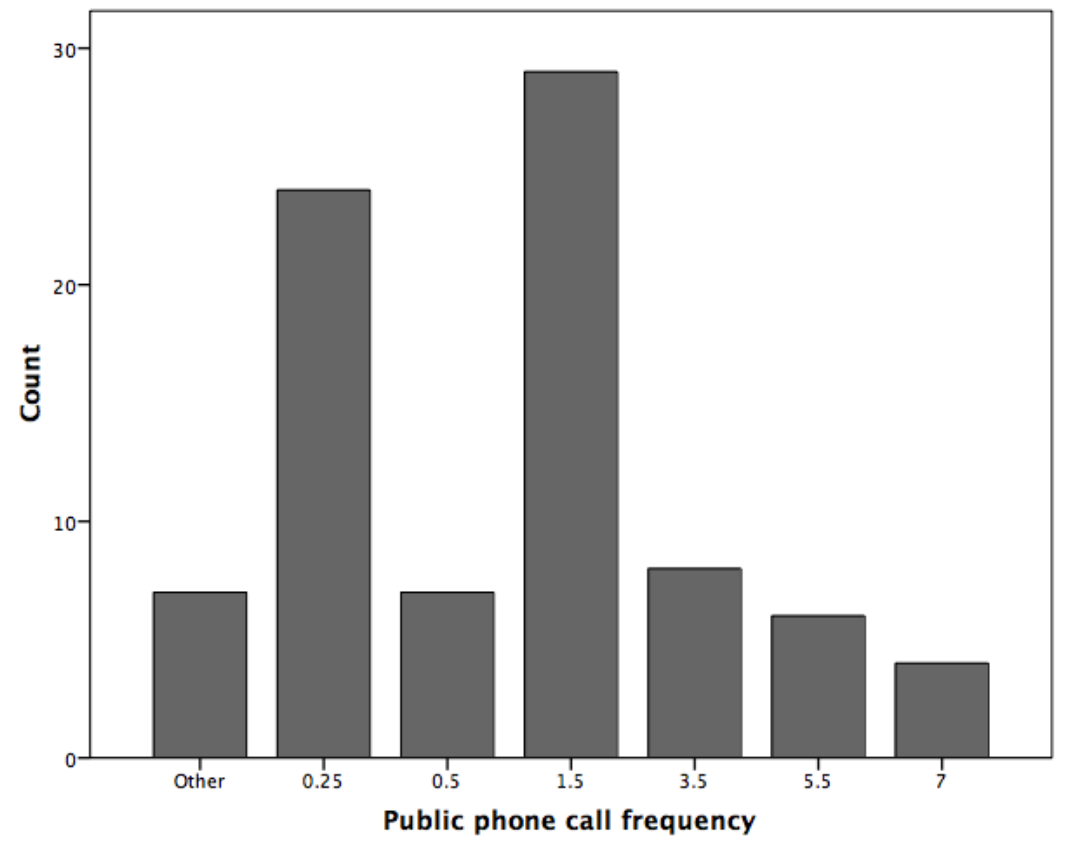

Figure 11: Histogram of public phone call frequency for the subset of public phone users 


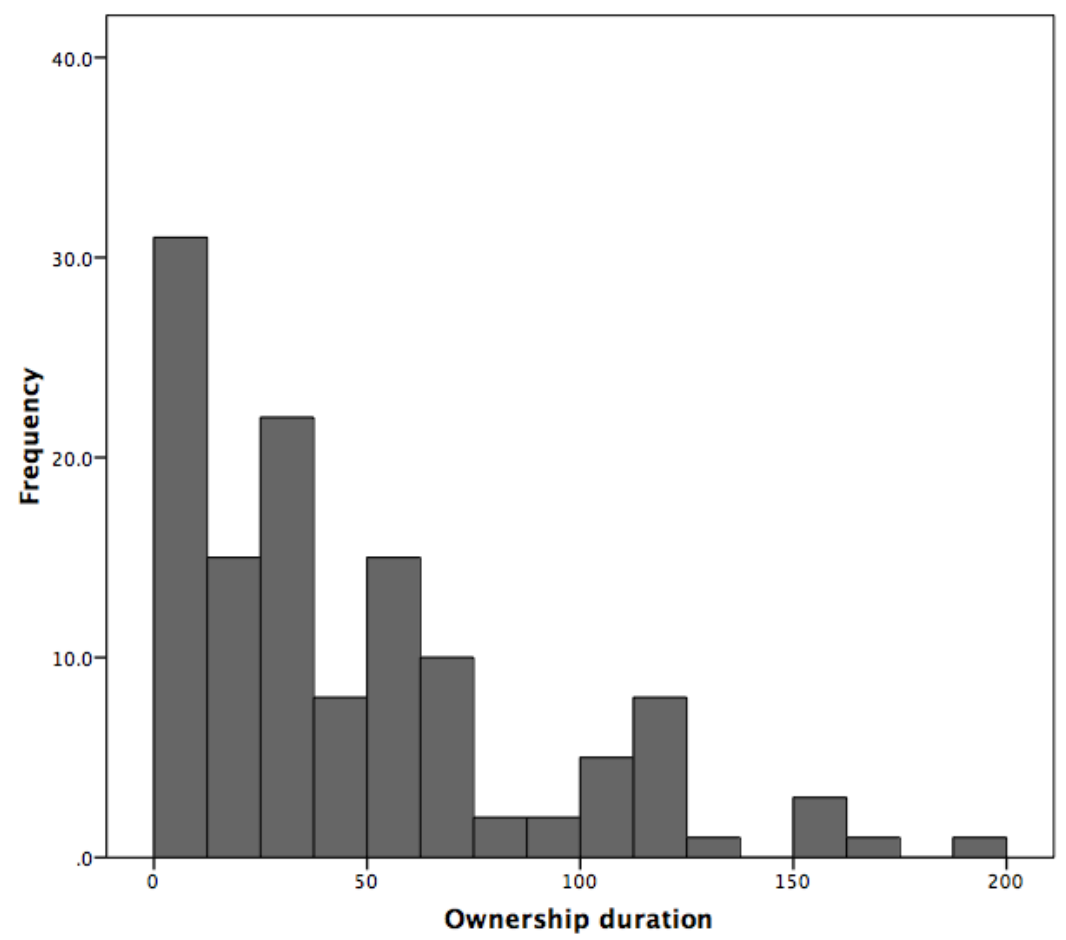

Figure 12: Histogram of ownership duration for the subset of mobile phone users

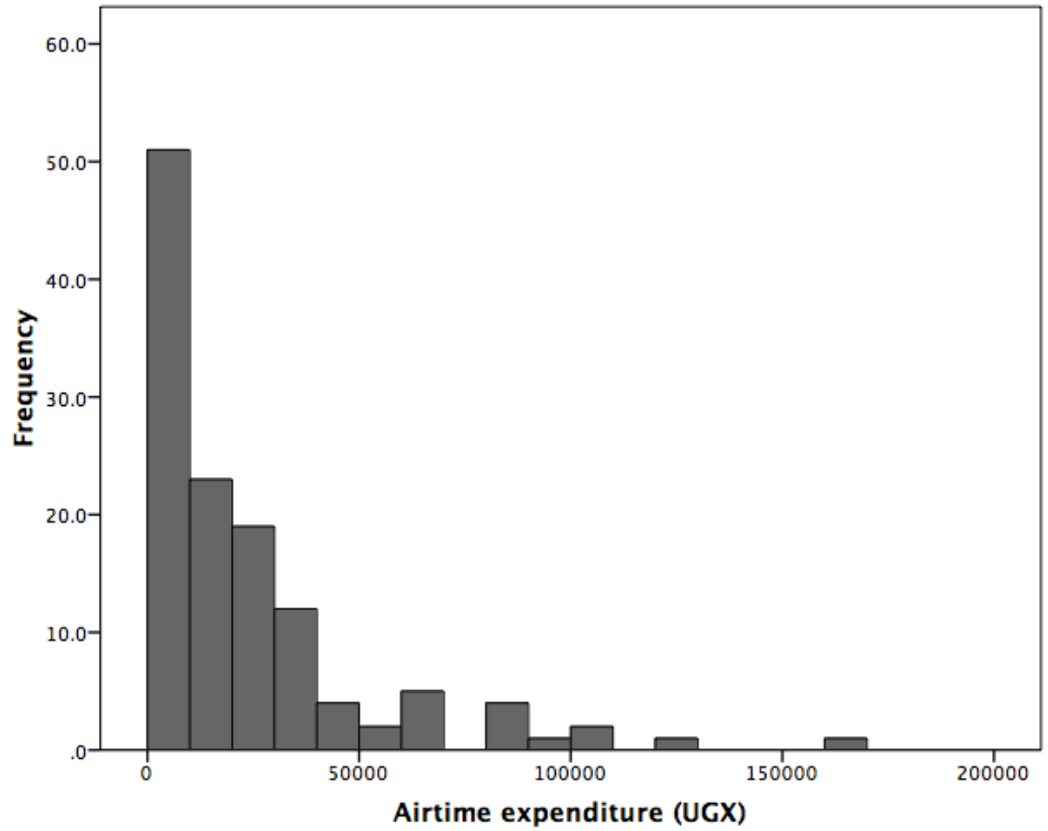

Figure 13: Histogram of airtime expenditure for the subset of mobile phone users 


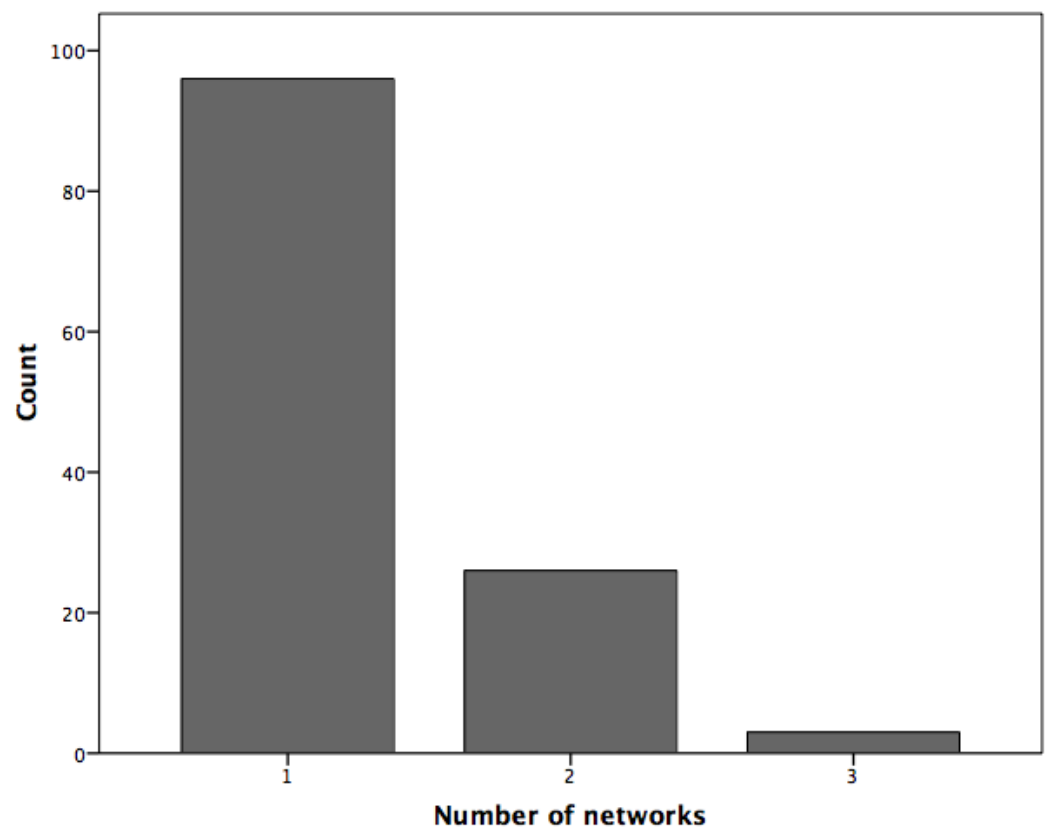

Figure 14: Histogram of number of networks used for the subset of mobile phone users

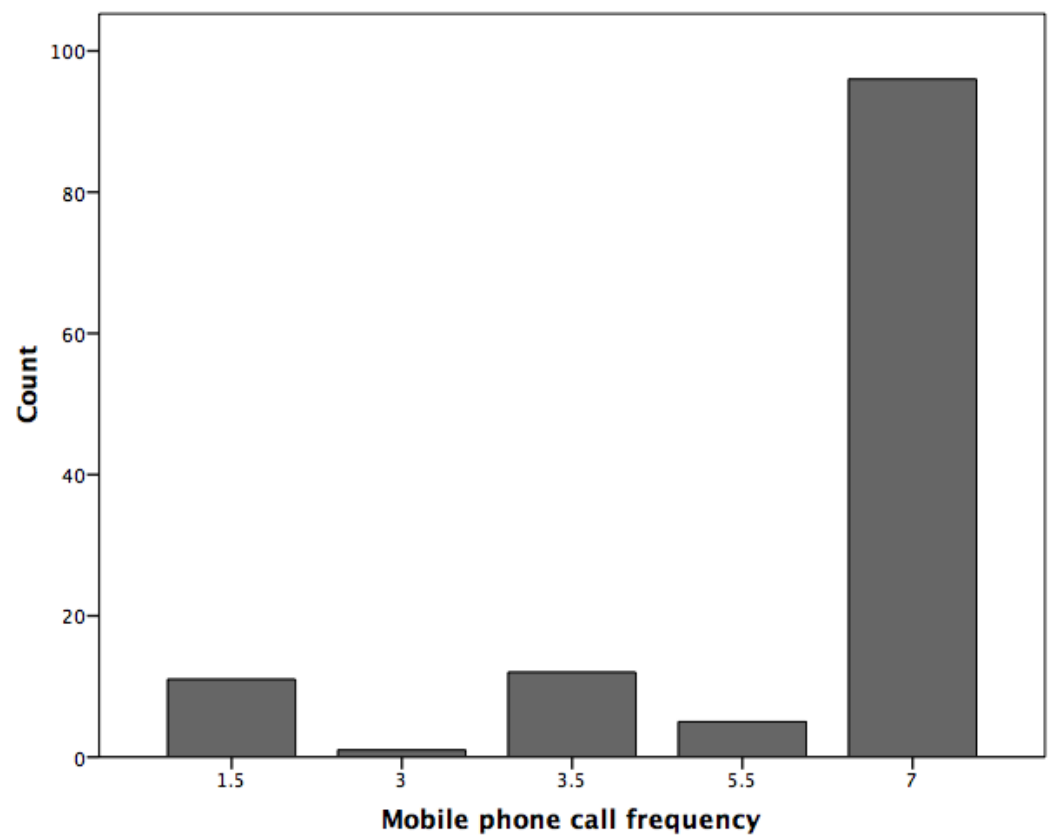

Figure 15: Histogram of mobile phone call frequency for the subset of mobile phone users 


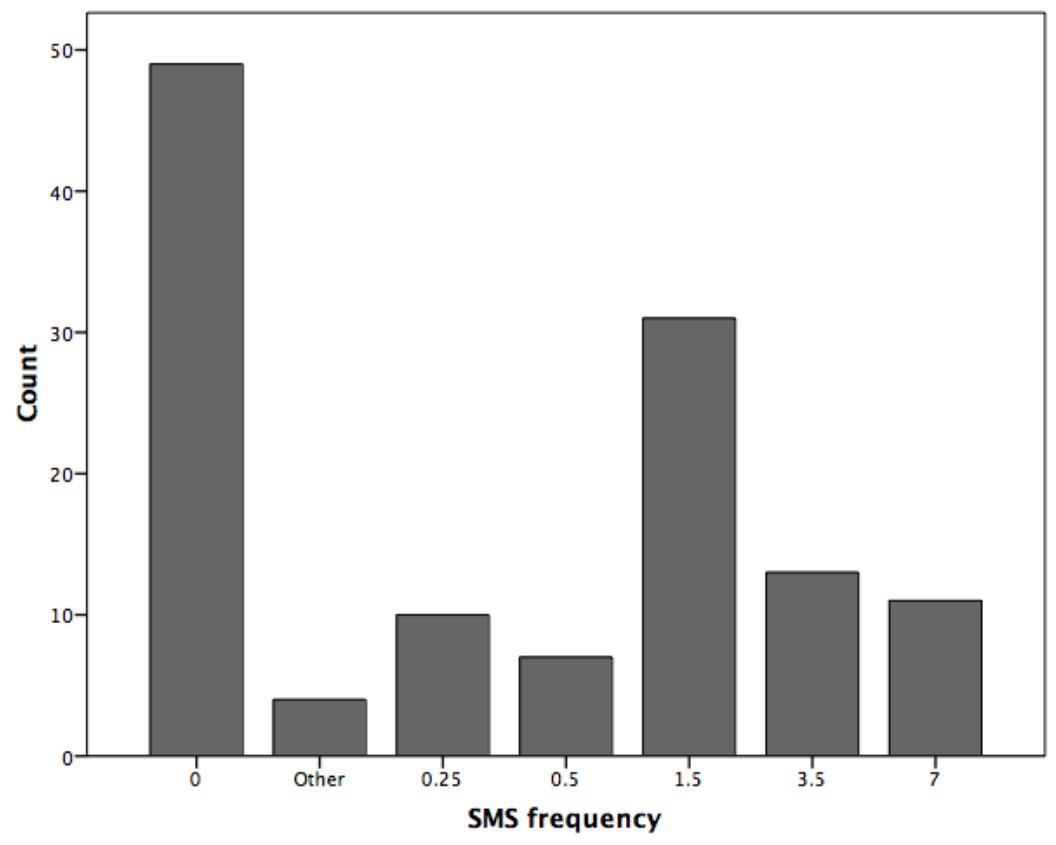

Figure 16: Histogram of SMS frequency for the subset of mobile phone users

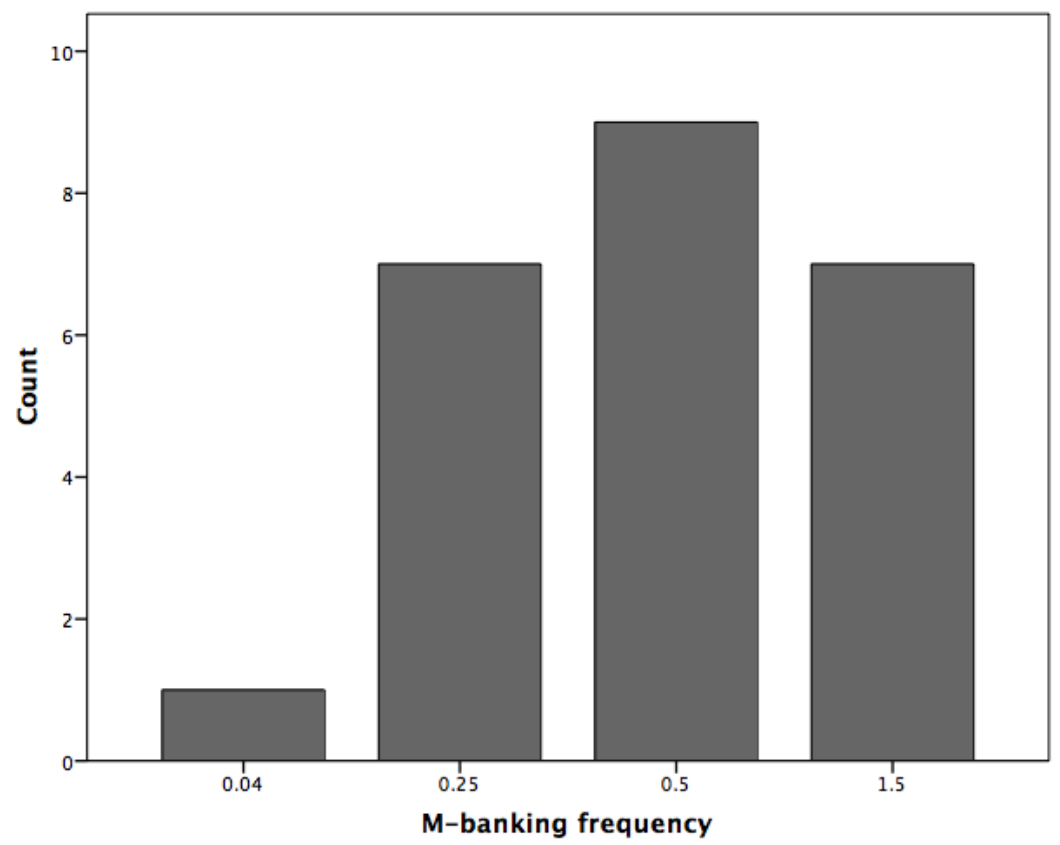

Figure 17: Histogram of m-banking frequency for the subset of m-banking users 


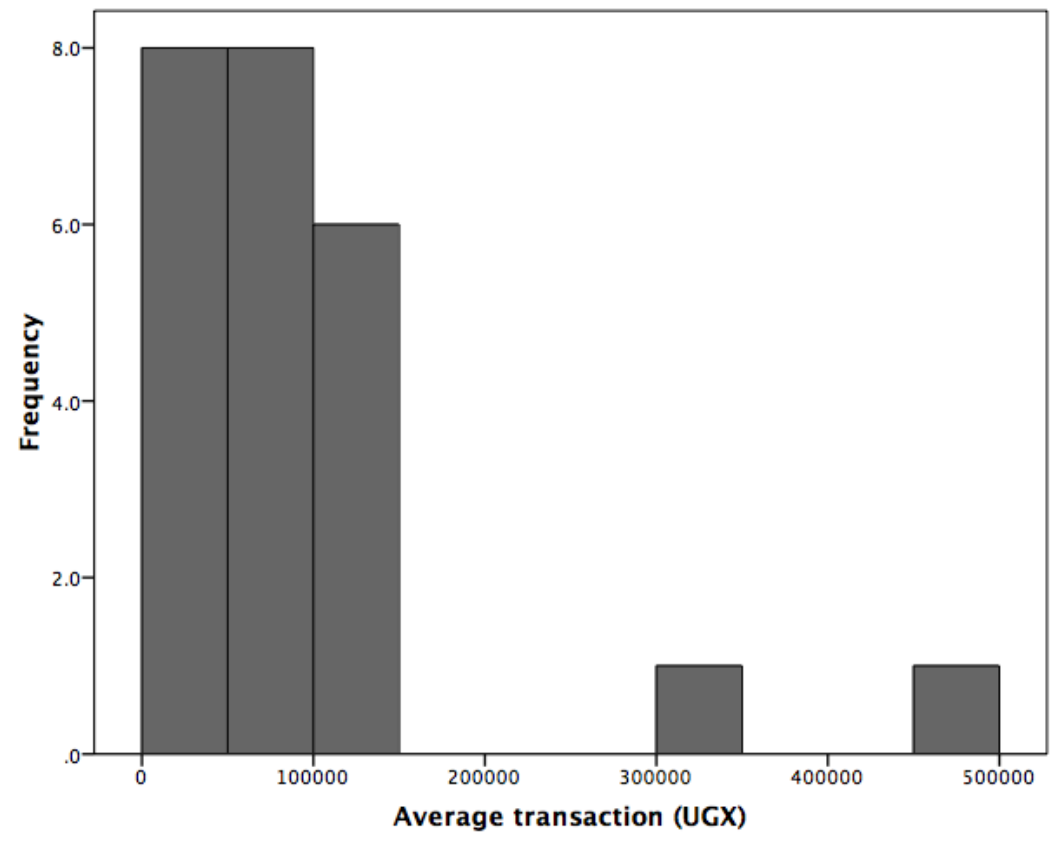

Figure 18: Histogram of average transaction for the subset of m-banking users

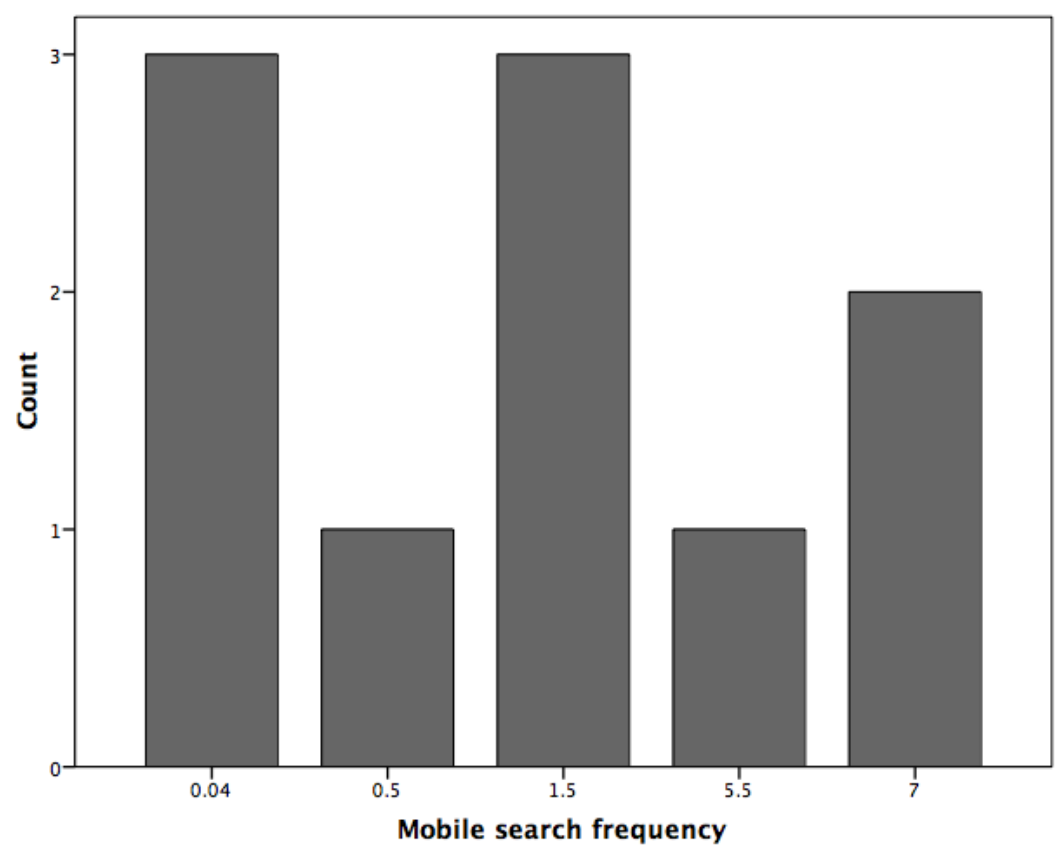

Figure 19: Histogram of mobile search frequency for the subset of mobile search users 
Appendix D: Descriptive statistics for geographic areas 


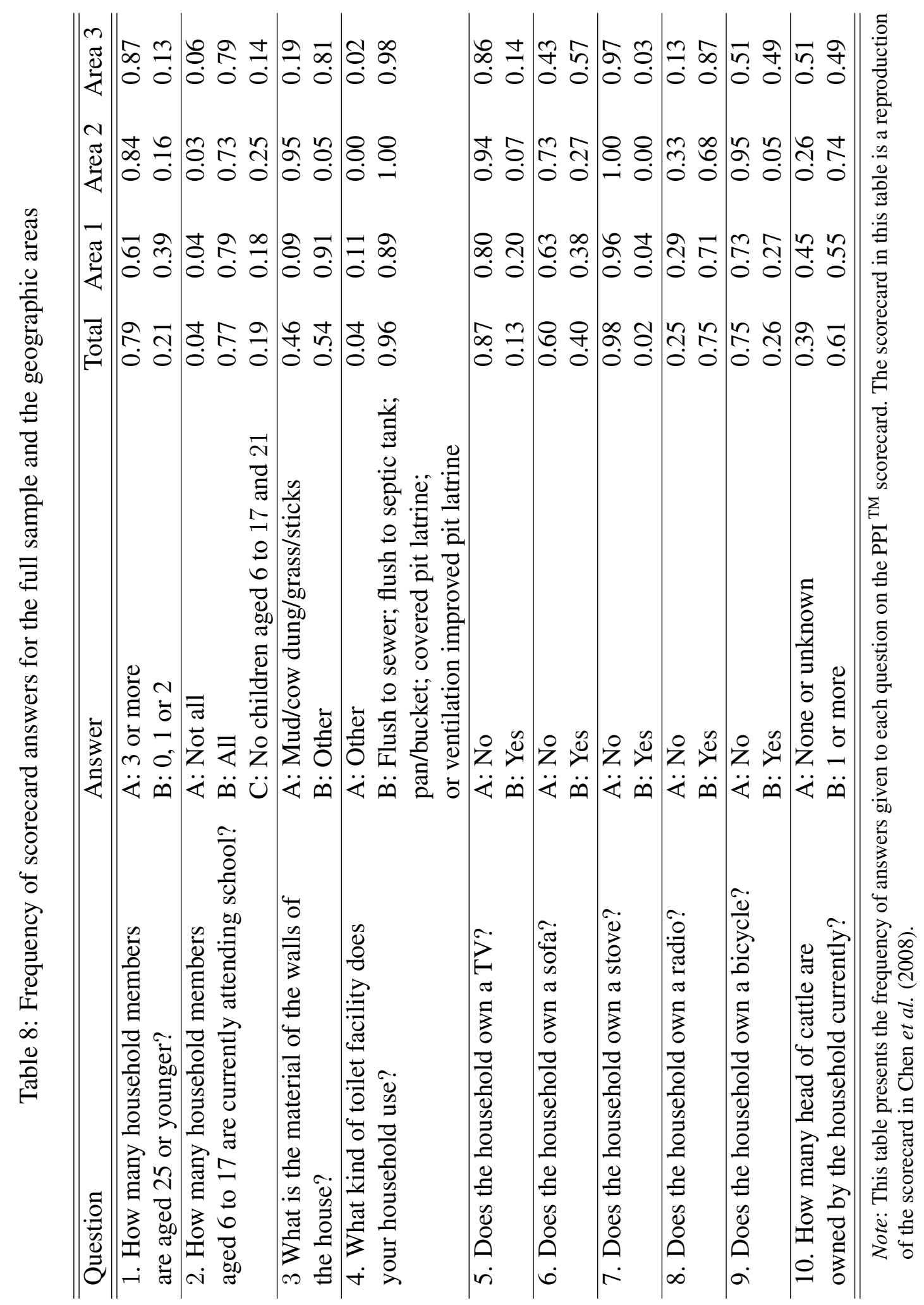




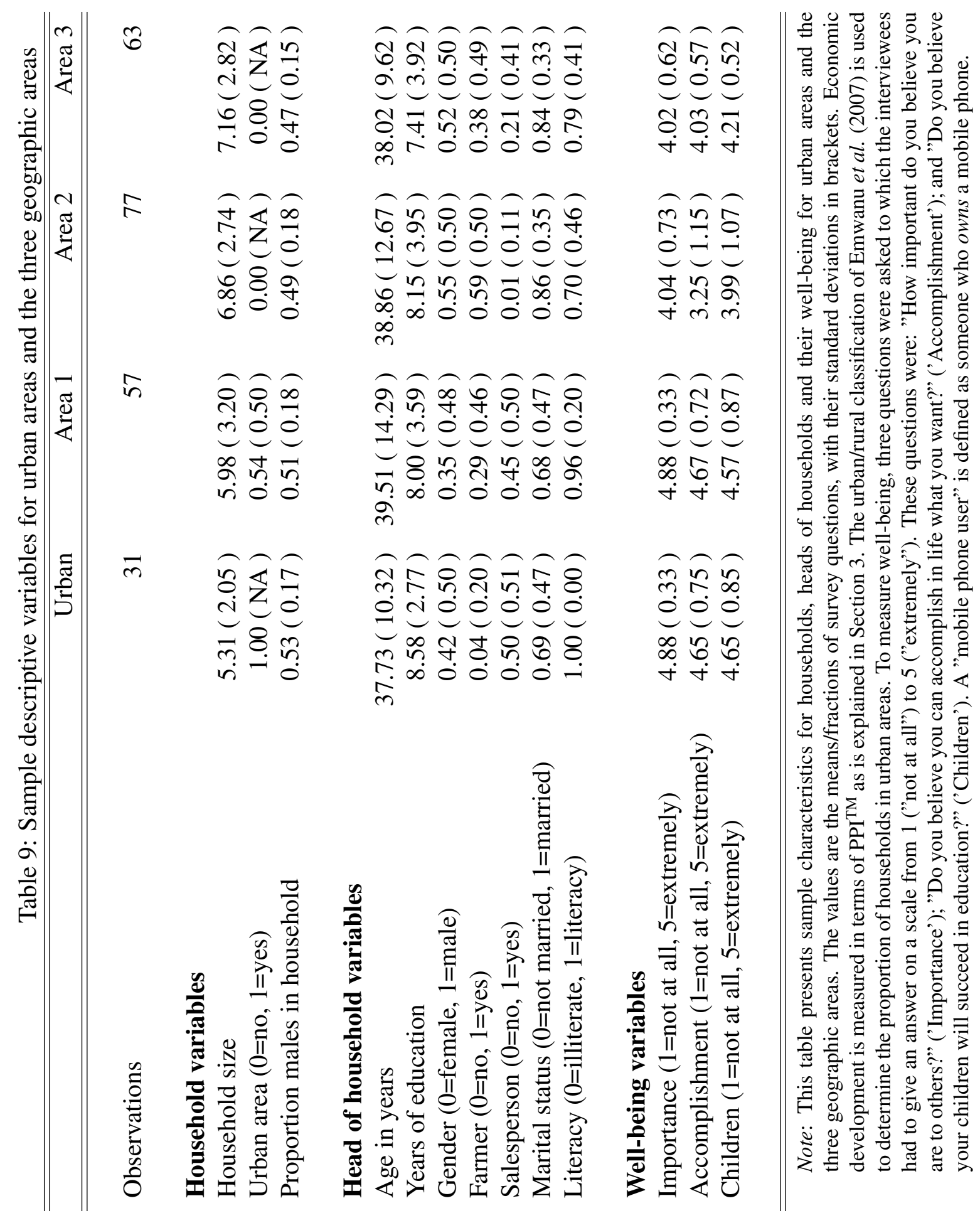




\section{Appendix E: Instrumental Variables}

Table 10: Full set of instruments and selected instruments for highest fit for each IV regressor set

\begin{tabular}{|c|c|c|c|}
\hline & \multicolumn{3}{|c|}{ Table 6} \\
\hline & ( a ) & ( b ) & (c) \\
\hline Gender $(0=$ female, $1=$ male $)$ & & & \\
\hline Age (in years) & & & \\
\hline Age squared & & & \\
\hline Marital status $(0=$ not married, $1=$ married $)$ & & & \\
\hline Public phone use $(0=$ no, $1=$ yes $)$ & + & + & \\
\hline Public phone frequency (days a week) & & & \\
\hline Public phone closer ( $1=$ not at all, $5=$ extremely) & & & + \\
\hline Distance of last phone call (kilometers) & + & + & \\
\hline Importance ( $1=$ not at all, $5=$ extremely) & & & \\
\hline Accomplishment ( $1=$ not at all, 5=extremely) & & & \\
\hline Children ( $1=$ not at all, $5=$ extremely $)$ & & & \\
\hline
\end{tabular}

Note: This table displays the full set of instruments used for each regression in this study. Each possible subset of instruments from the full set is used in a separate regression (see Section 4). The variables indicated with a ' + ' are used as instruments in the IV regression for the highest first stahe fit. See Section 3 for more information on the public phone variables, see Section 3 for more information on the well-being variables. The variable public phone closer represents the answer to the question "If a public phone was located closer to your house, would you use it more often?" 